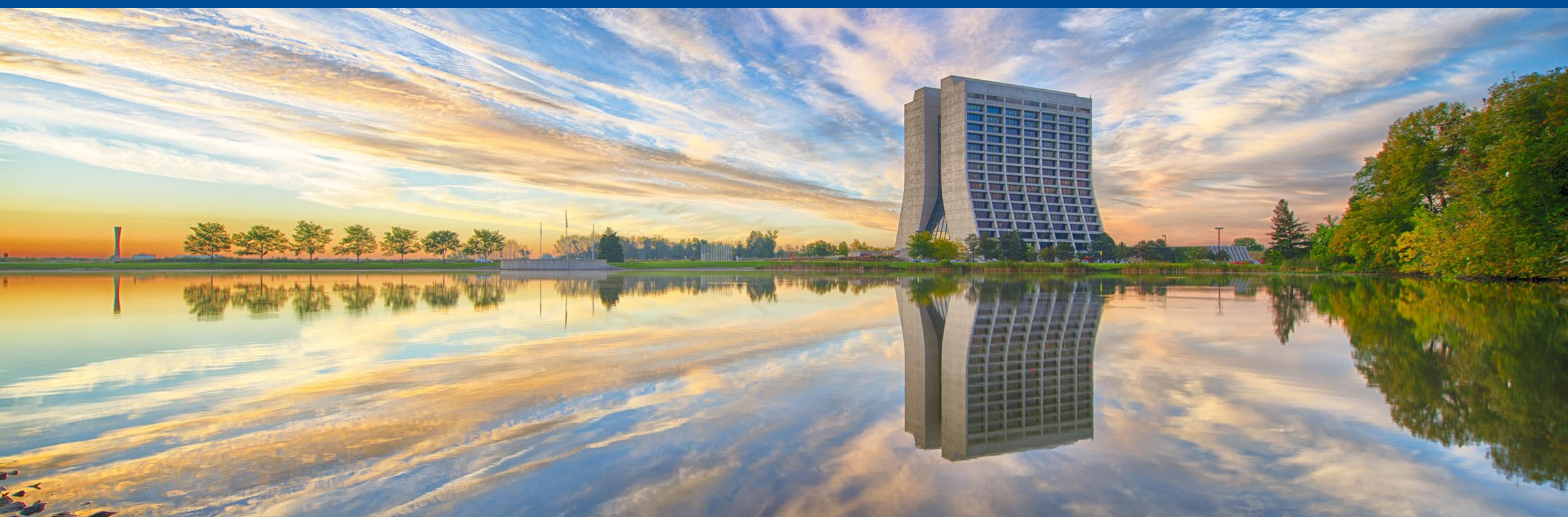

\title{
Compact, high-power superconducting electron linacs as irradiators for materials and radiation processing
}

Illinois Accelerator Research Center (IARC),

Fermilab 


\section{Accelerators for industry are different from collider machines!}

- Accelerators for industrial applications:

- Modest energy: few MeVs - tens of MeV

- Modest power: tens of $\mathrm{kW}$ - hundreds of kW.

- Specific requirements:

- Simplicity

- Low cost

- Reliability

- Work in industrial environment (harsh!)

- Easy to operate

- Small sizes

- High efficiency

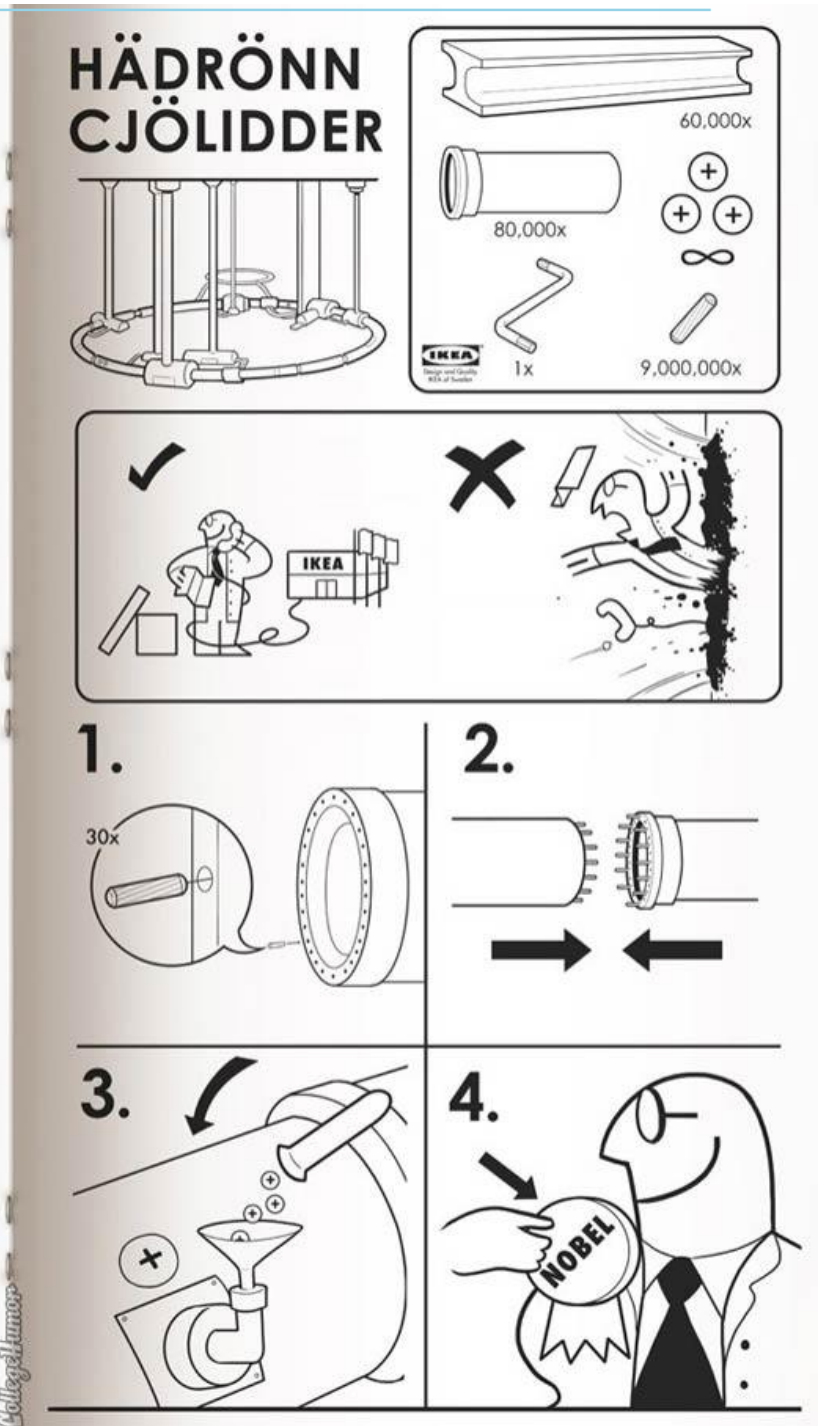




\section{Accelerators comes in several sizes and shapes.}

- Electrostatic (few keV - $10 \mathrm{MeV}$ ) - e.g. Dyanmitron, CockroftWalton, Pelletron

- Microtron - a cross of cyclotron but uses multi-pass

- Betatron - essentially a transformer but circular can reach several MeV's

- Rhodotron - recirculating through a coaxial cavity

- RF Linac (several MeV's) - normal conducting cavities

- Synchrotron

- Ion accelerators (different species) 


\section{Commercial electron beam (EB) accelerator applications}

\section{are vast}

- EB welding

- EB melting

- EB sterilization

- EB curing

- Non-destructive testing

- Medical imaging

- Cargo inspection

- Accelerators beyond electrons: Ion-implantation, boron neutron capture therapy, etc..

.....A steady market 


\section{Current vs New Accelerator Technology}

- Bulk materials processing applications require multi-MeV for penetration and 100's of kW (or even MW) of beam power

- $\quad>$ few MeV accelerators are typically copper and RF driven

- Inherent losses limit efficiency (heat vs beam power) = ops cost

- Heat removal limits duty factor, gradient and average power $\rightarrow$ physici large "fixed" installations = CAPEX

\section{New Technology: Superconducting Radio Frequency (SRF)}

- High wall plug power efficiency (e.g. 75\%)

- Large fraction of the input power goes into beam

- High power \& efficiency enables new \$1 Billion class SRF-based science machines $\rightarrow$ driving large R\&D efforts at labs

- Currently SRF-based science accelerators are huge with complex cryogenic refrigerators, cryomodules, etc. But this is changing!

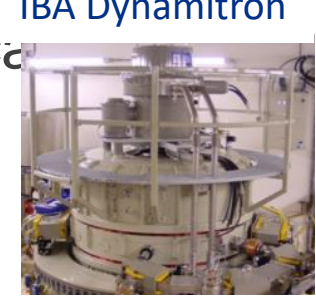

IBA Rhodotron

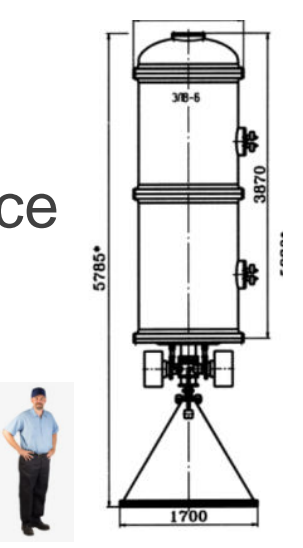

- Recent SRF breakthroughs now enable a new class of compact, SRFbased industrial accelerators (lower CAPEX and OPS cost) 
Current SRF "science" accelerators are large and complex

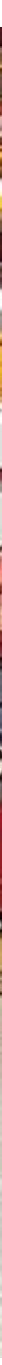




\section{IARC is building a simple, compact SRF accelerator for industrial applications}

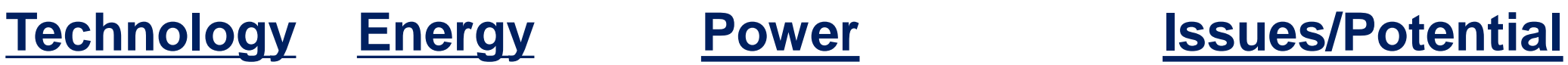

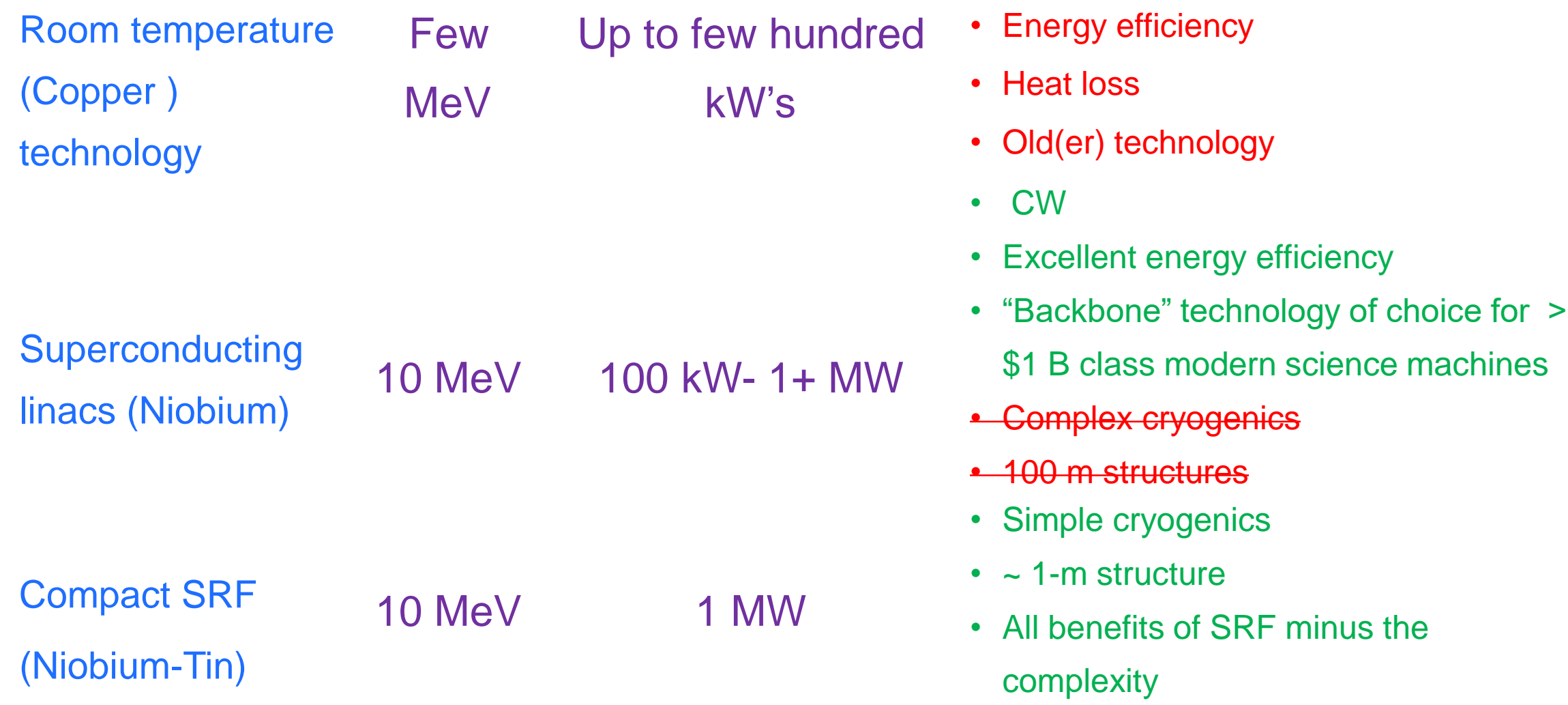




\section{Fermi National Accelerator Laboratory (DOE)}

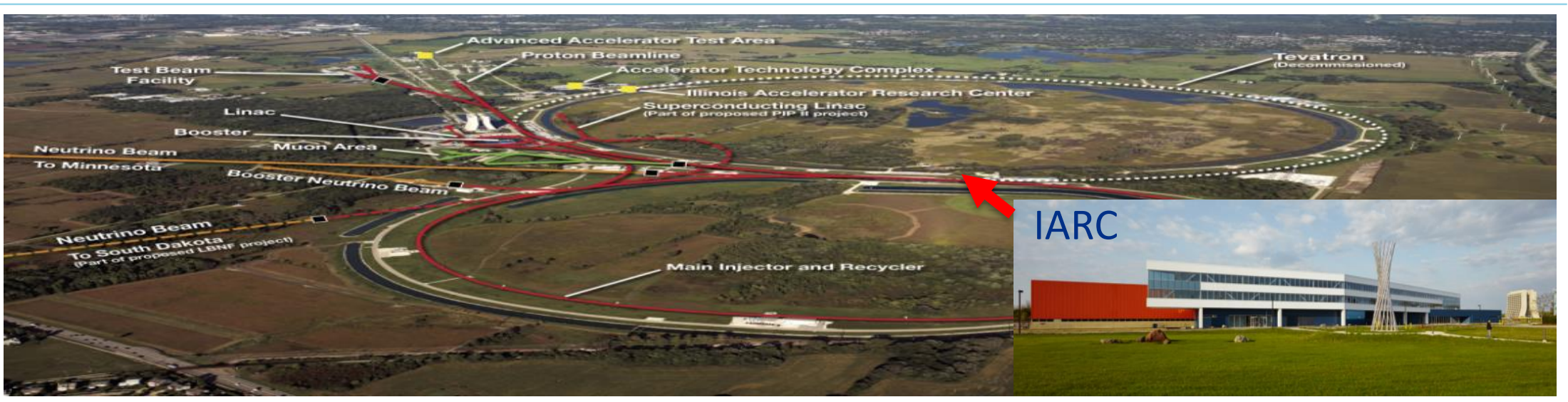

Mission: Discovery Science High Energy Physics $\rightarrow$

Build \& operate: High Energy \& Power (MW) Accelerators 6800 acre site, $\sim \$ 360 \mathrm{M} / \mathrm{yr}$, Staff of $1700,>2200$ users 650 Accelerator scientists, engineers + technical staff Broad skills in accel. design, simulation, fabrication, \& test NEW: The Illinois Accelerator Research Center (IARC)

- Mission: Exploit technology developed in pursuit of science to enable new industrial accelerator applications \& businesses 


\section{Accelerator Applications enabled by modern advancements.}

\section{Energy and Environment}

- Treat Municipal Waste \& Sludge

- Eliminate pathogens in sludge

- Destroy organics, pharmaceuticals in waste water

- In-situ environmental remediation

- Contaminated soils

- Spoils from dredging, etc
Industrial and Security

- In-situ cross-link of materials

- Improve pavement lifetime

- Instant cure coatings

- Medical sterilization without Co60

- Improved non-invasive inspection of cargo containers

- Additive manufacturing refractory metals

These new applications need cost effective, energy efficient, high average power electron beams.

SRF-based science accelerators are huge with complex cryogenic refrigerators, cryomodules, etc.

Recent SRF breakthroughs now enable a new class of compact, SRF-based industrial accelerators (lower CAPEX and OPS cost) 


\section{Recent SRF Technology Breakthroughs:}

- Higher temperature superconductors: $\mathrm{Nb}_{3} \mathrm{Sn}$ coated cavities dramatically lower cryogenic losses and allow higher operating temperatures (e.g. $4 \mathrm{~K}$ vs $1.8 \mathrm{~K}$ )

- Commercial Cryocoolers: new devices with higher capacity at $4 \mathrm{~K}$ enables turn-key cryogenic systems

- Conduction Cooling: possible with low cavity losses $\rightarrow$ dramatically simplifies cryostats (no Liquid Helium !)

- New RF Power technology: injection locked magnetrons allow phase/amplitude control at high efficiency and much lower cost per watt

- Integrated electron guns: reduce accelerator complexity Enable compact industrial SRF accelerators at low cost 


\section{Ideas integrated into a simple SRF accelerator}

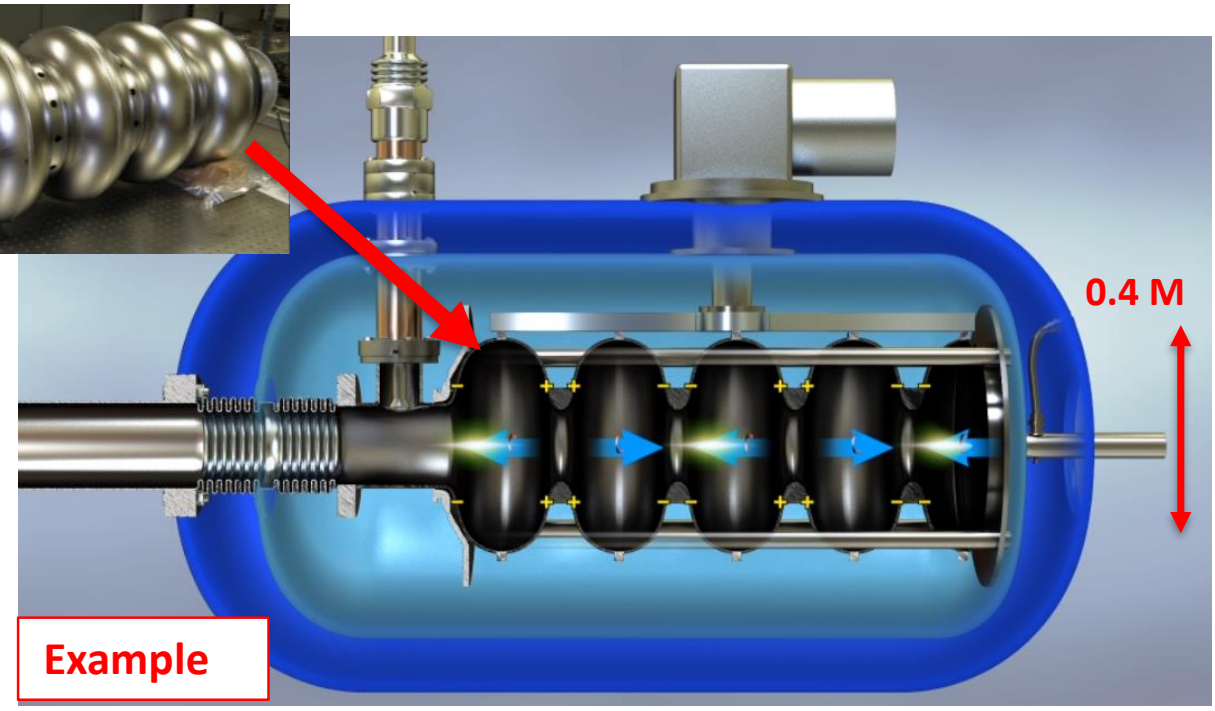

Final machine parameters

- Energy: $10 \mathrm{MeV}$

- Power: $250 \mathrm{~kW}$ - $1 \mathrm{MW}$

- Compact

- Simple, reliable

- Affordable

- $650 \mathrm{MHz}$ elliptical cavity (well understood from PIP-II)

- Modular design scales to MW class industrial applications

Staged approach: First demonstrate a $30 \mathrm{~kW}$ prototype including all the key technologies 


\section{Developing a $250 \mathrm{KW}$ skid mount Version}

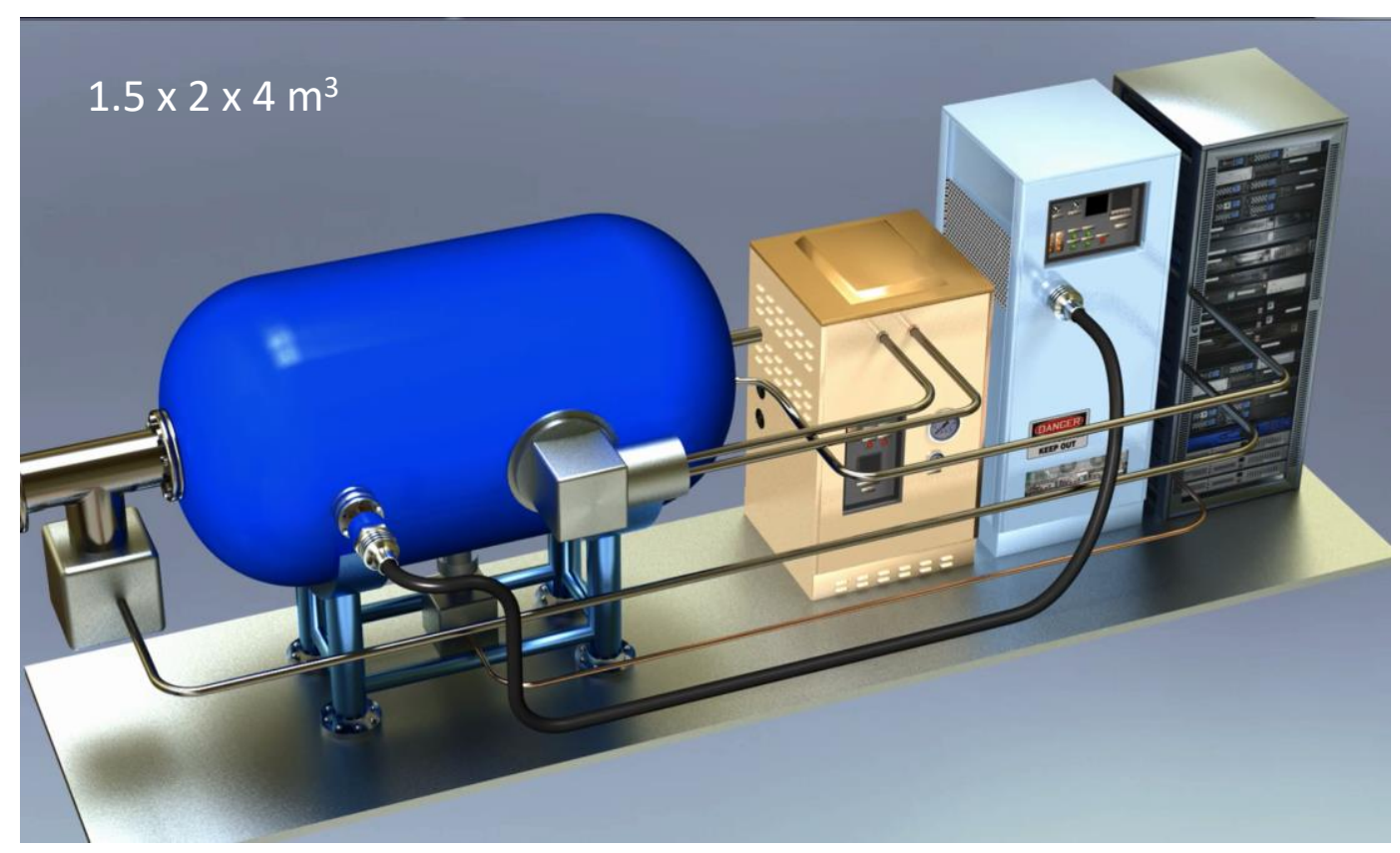

- Mobile high power accelerators enable new applications

- In-situ environmental or cross link applications

- DOE funds for conceptual design \& key technologies

- Funding from DOD (USACE), interest from DHS, NNSA

- Goal: Create a new class of industrial SRF accelerators! 


\section{In-Situ Cross-Link of Materials}

Electron accelerators are widely used to cross link materials

- High power mobile accelerators enable entirely new construction techniques that can alter materials properties after placement

- e.g. Improve the strength, toughness, and/or temperature range

- One applications: Improved Pavement

- US Army Corps of Engineers partnership (FY17 ERDC funding)
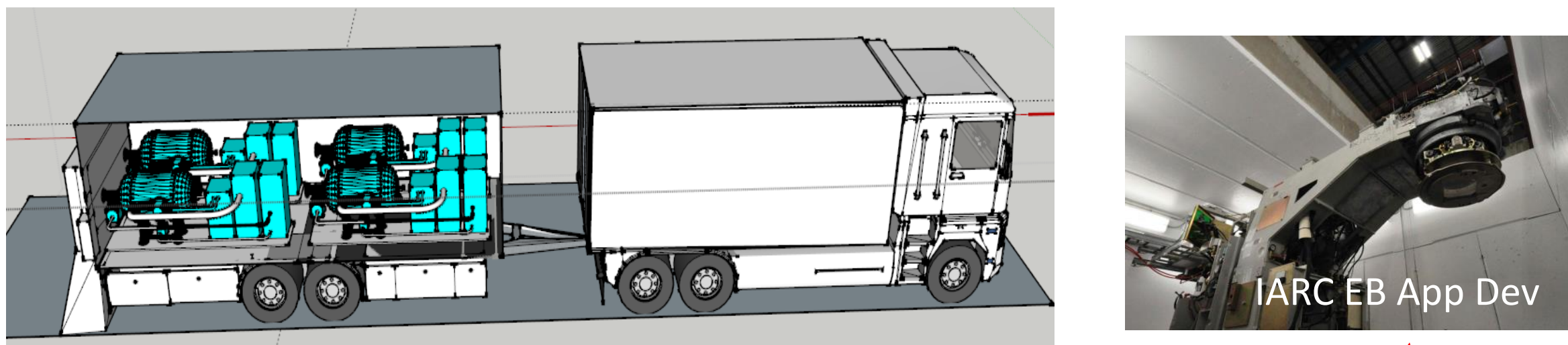

- Collaborating to create a tough, strong binder with improved temperature performance vs bitumen to extend pavement lifetime

- We have a small development facility A2D2 for rapid sample testing. 


\section{The Compact SRF Accelerator}

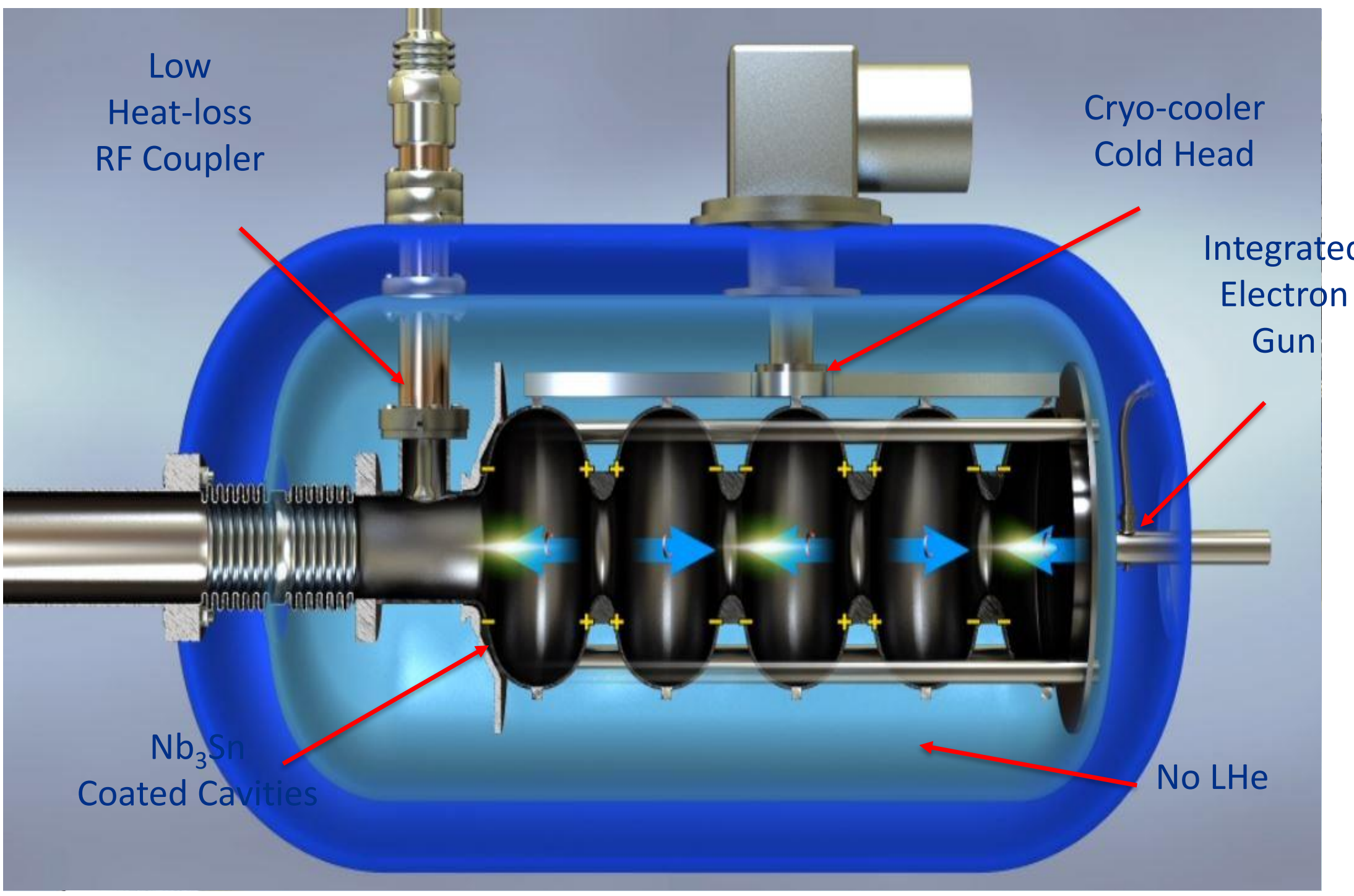




\section{In-situ Environmental Remediation}

- Since e-beams can disinfect or destroy organic compounds

- One can envision mobile SRF based accelerators for environmental remediation \& decontamination.

- Examples

- Clean soil contaminated by chemical spills

- Destroy biohazards or toxins

- In-situ decontamination of equipment, HAZMAT suits, area

- Wastewater treatment

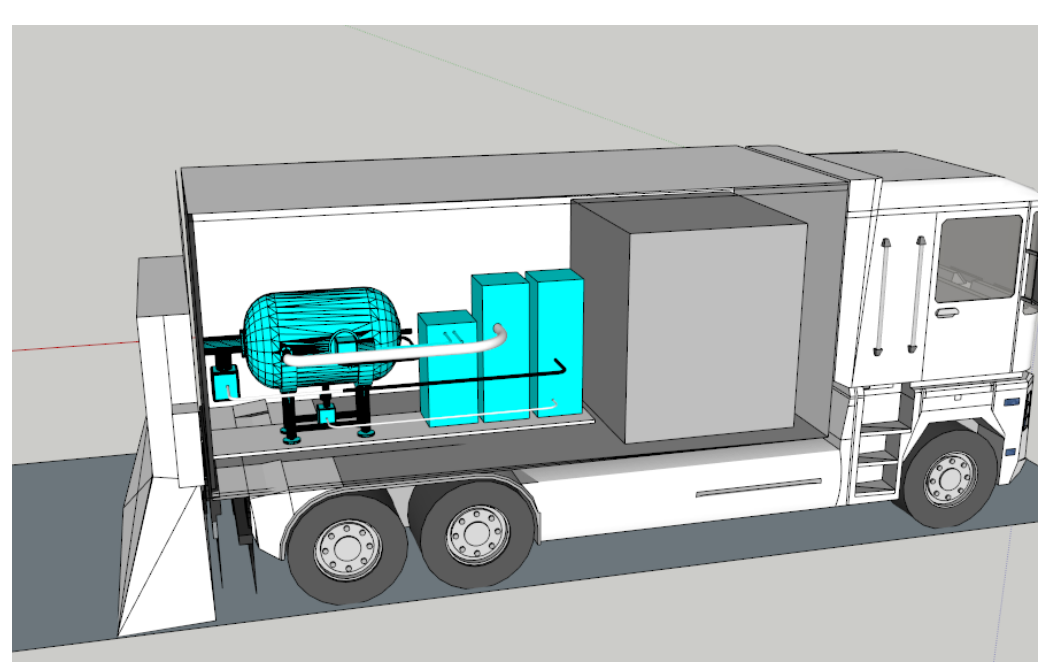

- Requires robust, reliable, compact, mobile accelerators that can be "brought to the problem" 


\section{General concept of RF Gun design}

Prototype for a $30 \mathrm{~kW}$ project employ internal injection, i.e. electron gun placed directly next to the SC $650 \mathrm{MHz} 1.5$ cells cavity.

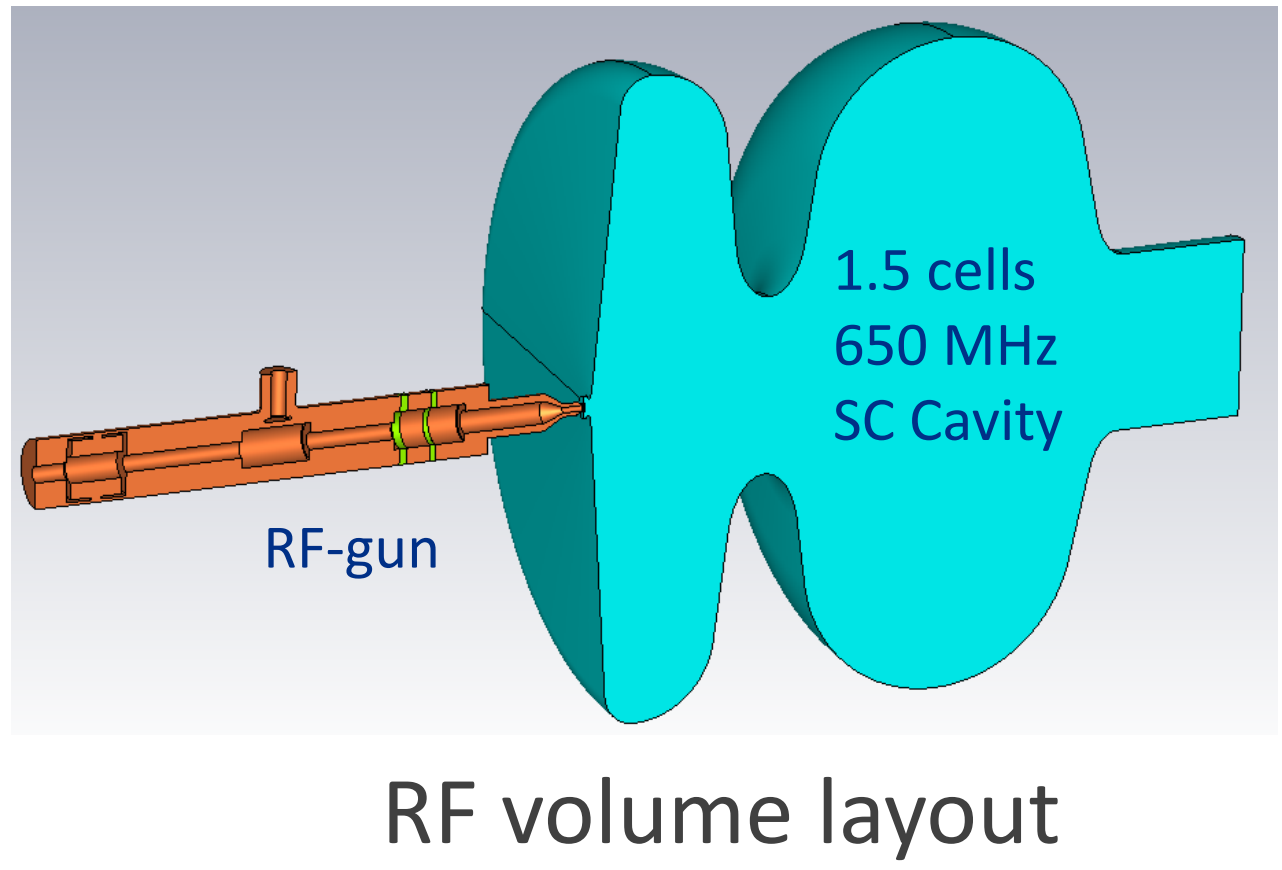

$$
\text { RF - Gun parameters }
$$

\begin{tabular}{|c|c|c|}
\hline F & 650 & $\mathrm{MHz}$ \\
\hline Energy & 1.6 & $\mathrm{MeV}$ \\
\hline Current & 18.5 & $\mathrm{~mA}$ \\
\hline Power & 30 & $\mathrm{~kW}$ \\
\hline Duty factor & $1-100$ & $\%$ \\
\hline Beam loss at 4K & $<1$ & $\mathrm{~W}$ \\
\hline Cathode radiation & $<0.5$ & $\mathrm{~W}$ \\
\hline Beam energy spread & $<10$ & $\%$ \\
\hline Beam phase size rms & $<10$ & $\circ$ \\
\hline
\end{tabular}




\section{Progress of RF Gun design}
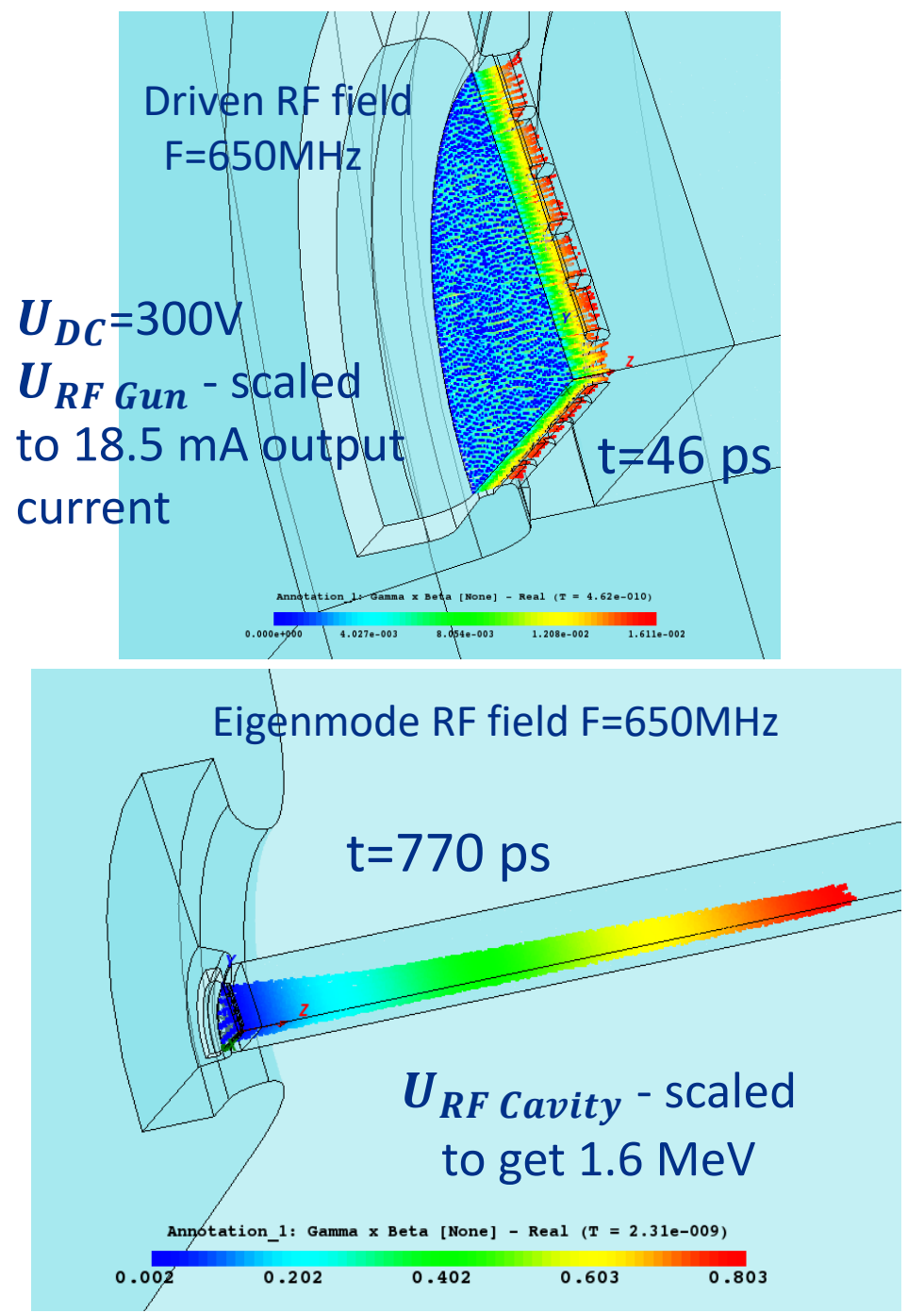

\section{MICHELLE design In progress}

1. $\mathrm{U}_{\mathrm{DC}}, \mathrm{U}_{\mathrm{RF} \text { Gun }}, \mathrm{U}_{\mathrm{RF} \text { Cavity }}$

2. Scale factor $L_{1} / L_{2}$

3. Enhancement factor $E_{1} / E_{2}$

4. Cathode-grid area

- $\mathrm{R}, \mathrm{L}$ dimensions

- Grid profile

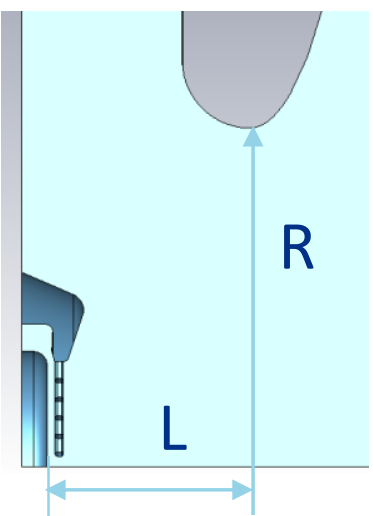




\section{Current SRF "science" accelerators are large and complex}

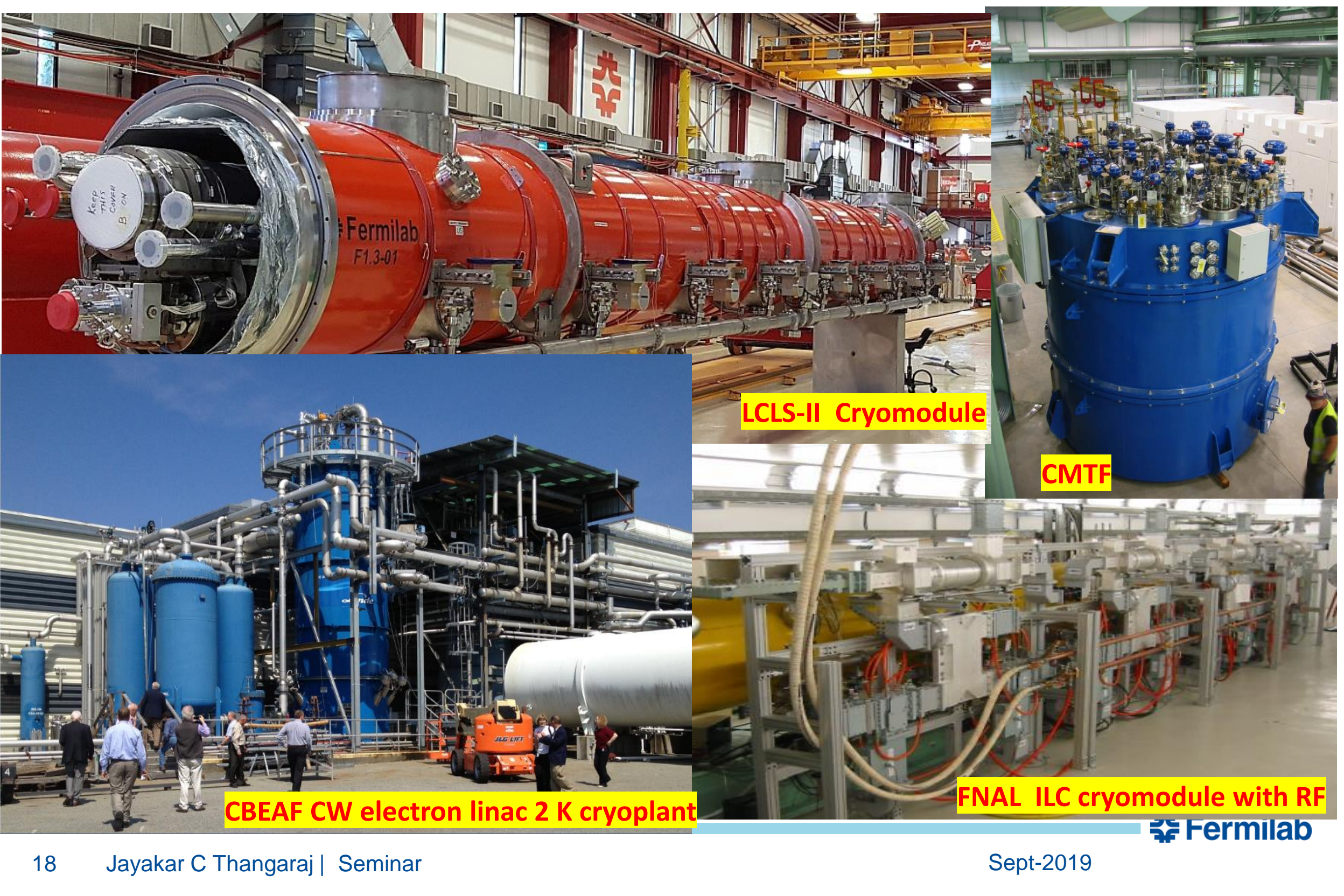




\section{Vision: Access SRF technology minus the complexity}

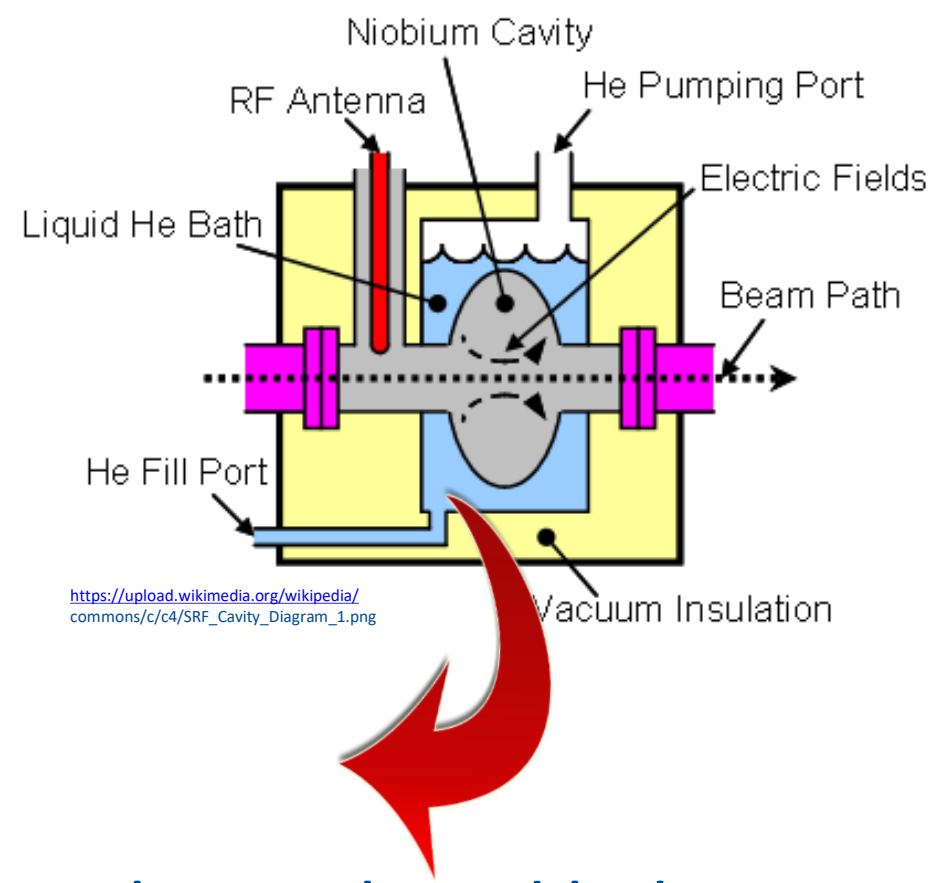

Take out liquid helium (and its complexities)
Cool with a cryocooler (simpler refrigerator)

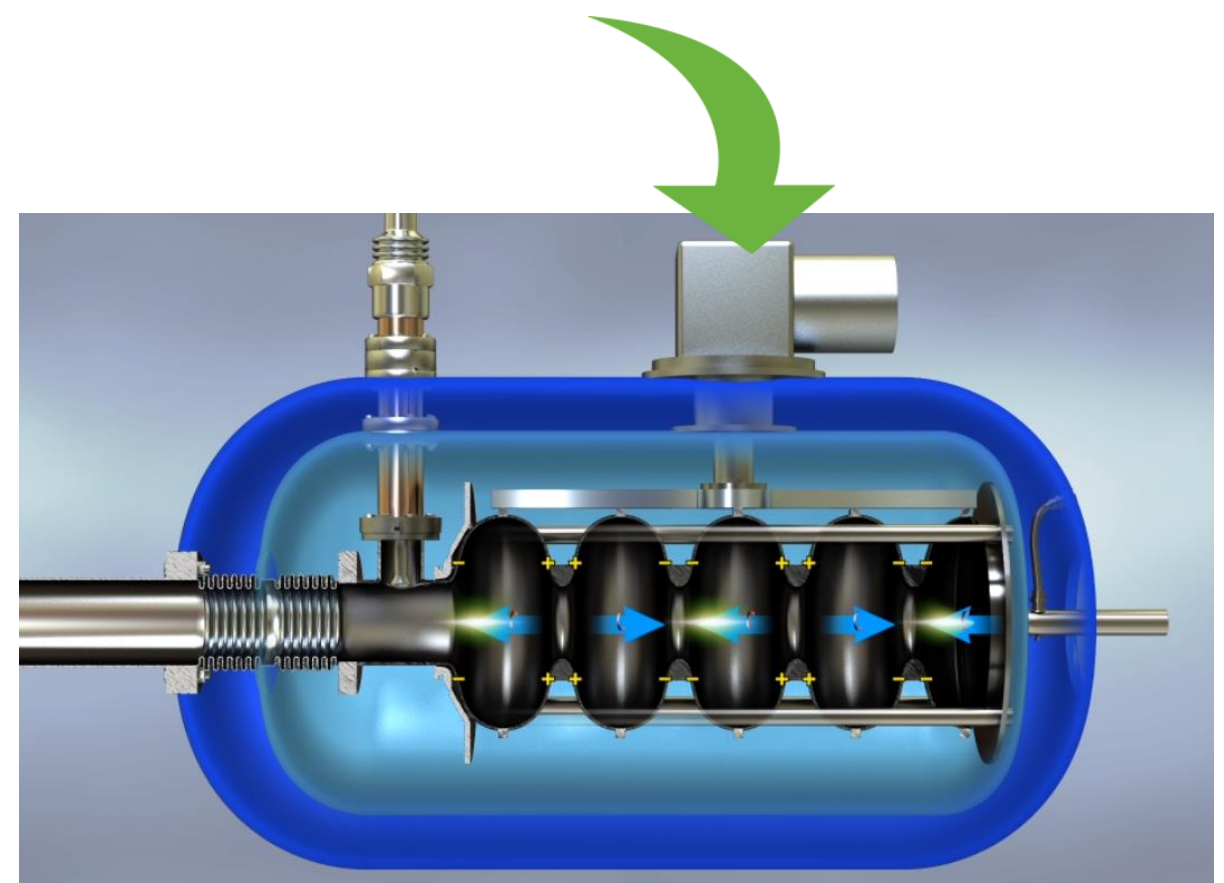




\section{Why now? I heard High-Tc superconductors are decades old}

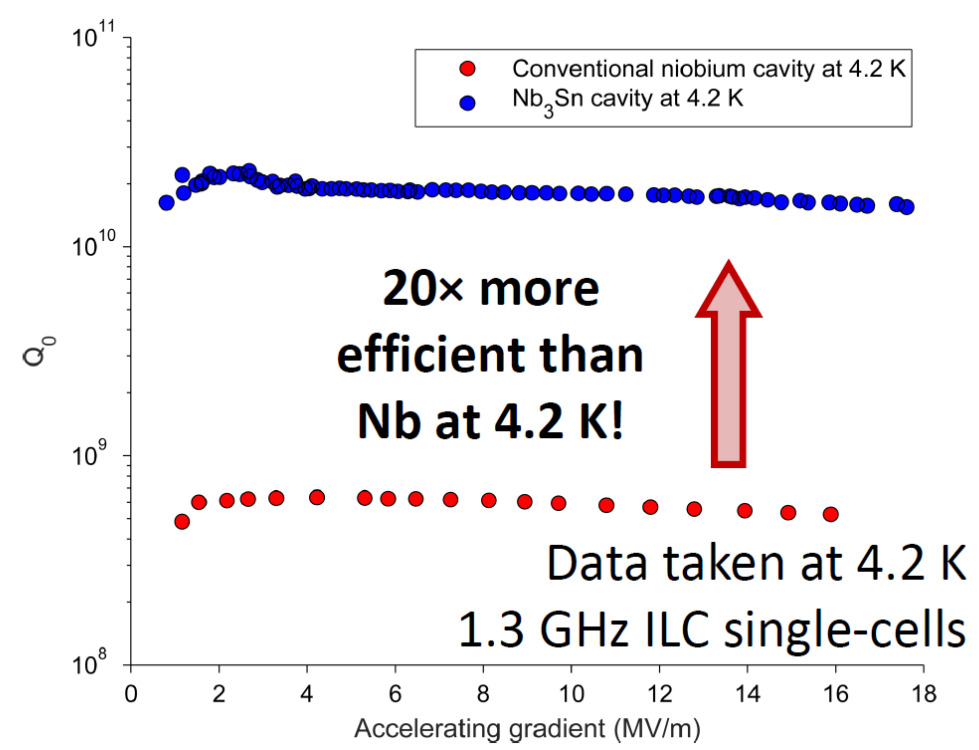

Nb3Sn coated SRF cavities

(S.Posen et al.):

dramatically lower cryogenic losses and allow higher operating temperatures (e.g. $4 \mathrm{~K}$ vs $2 \mathrm{~K}$ )

Commercial $4 \mathrm{~K}$ cryocoolers:

- Compact refrigerators operating near $4 \mathrm{~K}$, no liquid helium

- High reliability (MTTS 20000 hrs), turn on and off with push of a button

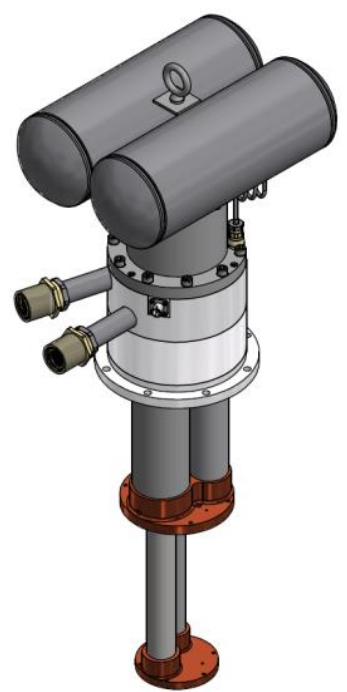




\section{General concept of $\mathrm{Nb}_{3} \mathrm{Sn}$ Films}

- Traditional niobium has tens of watts of dissipation at $4.4 \mathrm{~K}$

- $\mathrm{Nb}_{3} \mathrm{Sn}$ film provides order of magnitude smaller heat load for same conditions

- $\mathrm{Nb}_{3} \mathrm{Sn}$ goals:

- Establish capability of coating cavities with high performance at Fermilab

- Develop $\mathrm{Nb}_{3} \mathrm{Sn}$ coating at 650 $\mathrm{MHz}$ (larger cavity)

- Develop $\mathrm{Nb}_{3} \mathrm{Sn}$ coating of multicell cavities
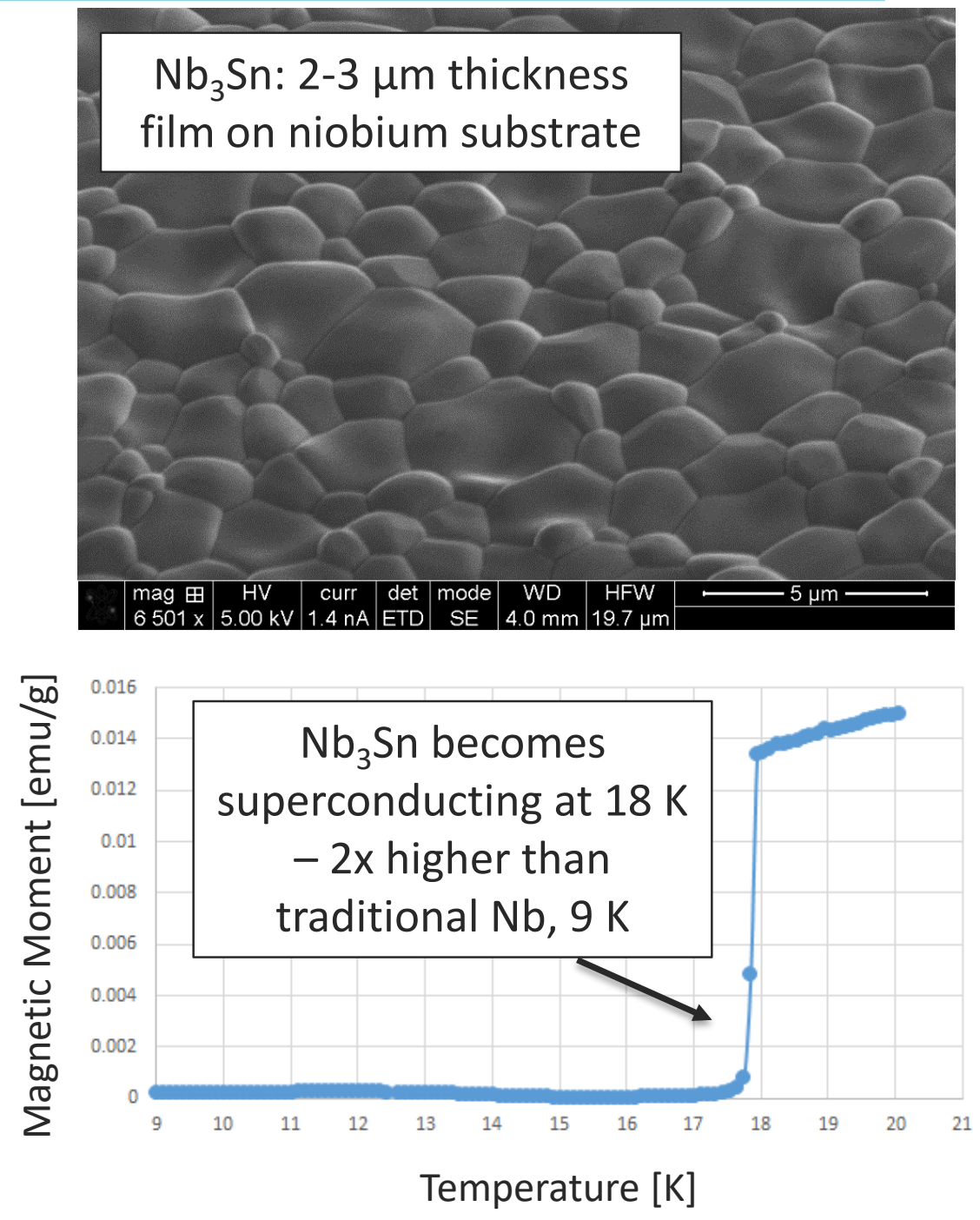


\section{Progress of $\mathrm{Nb}_{3} \mathrm{Sn}$ Films}

- Frequency dependence of $R_{B C S}, R_{r e s}$, quench, sensitivity

- $650 \mathrm{MHz}$ is an interesting step between scaling up form a 1cell 1.3 GHz to a 9-cell $1.3 \mathrm{GHz}$ cavity

- Better understand how vapor diffusion process scales with different sized substrates

Fermilab $\mathrm{Nb}_{3} \mathrm{Sn}$ SRF program: a number of $1.3 \mathrm{GHz}$ cavities already coated and tested; these are the first $650 \mathrm{MHz}$ and $3.9 \mathrm{GHz}$ cavities
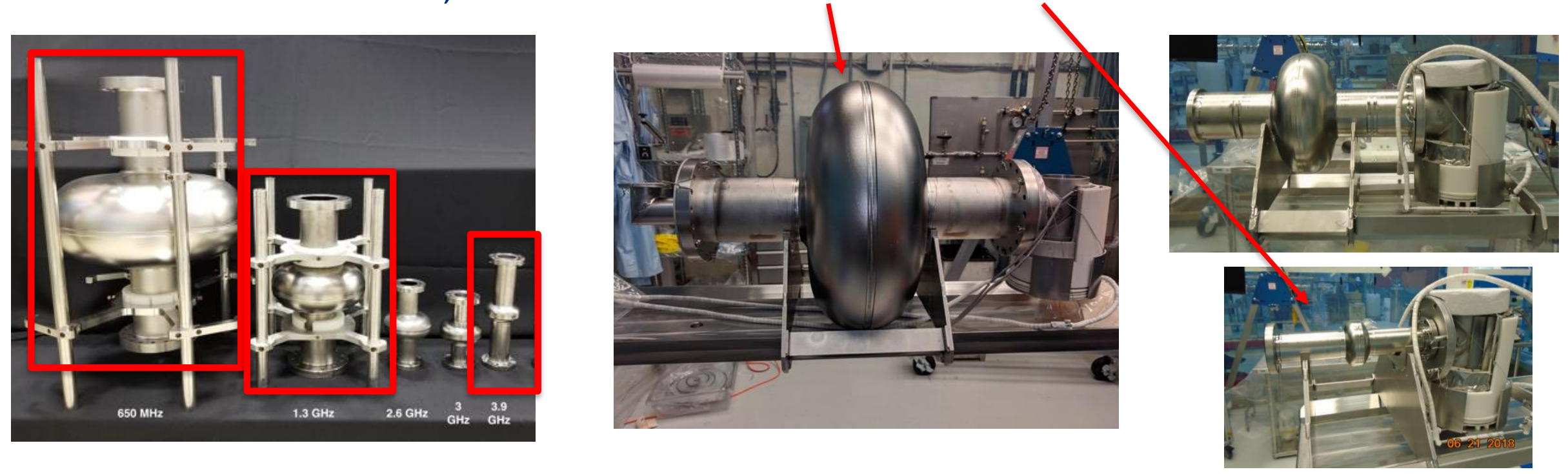

출 Fermilab 


\section{Design of the conduction cooled cryostat}

Cryostat will provide vacuum, low magnetic field, $4 \mathrm{~K}$ environment for the SRF accelerator cavity

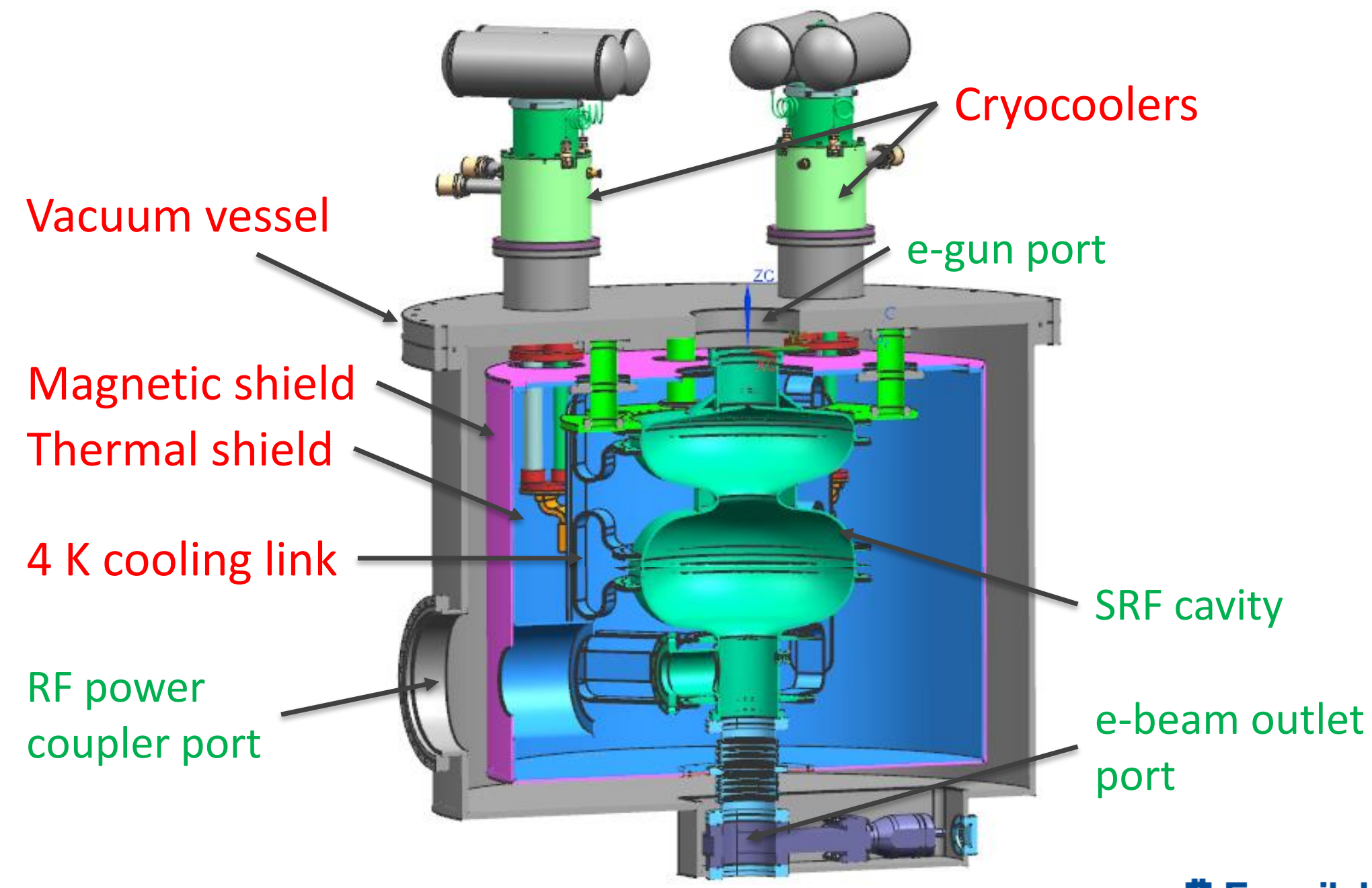




\section{Order of magnitude reduction}

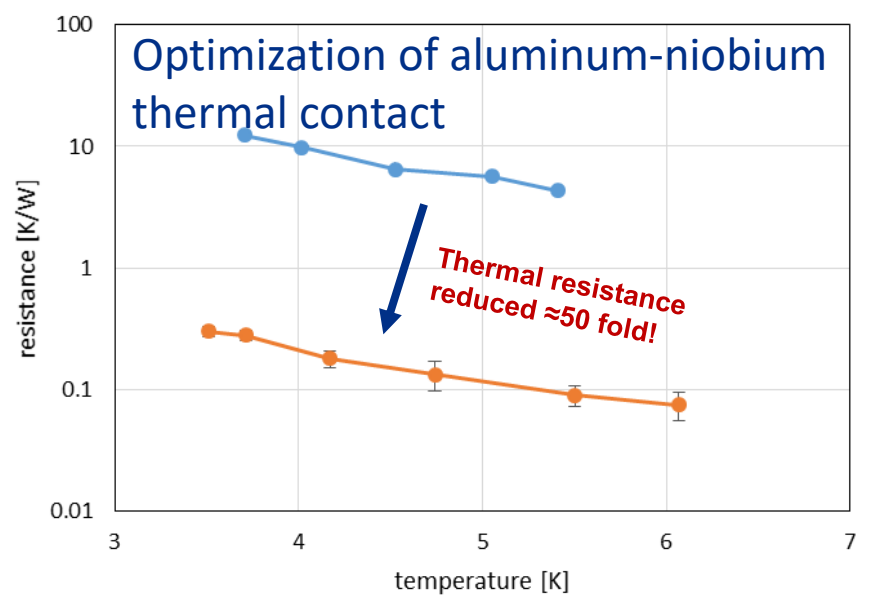

Thermal link simulations
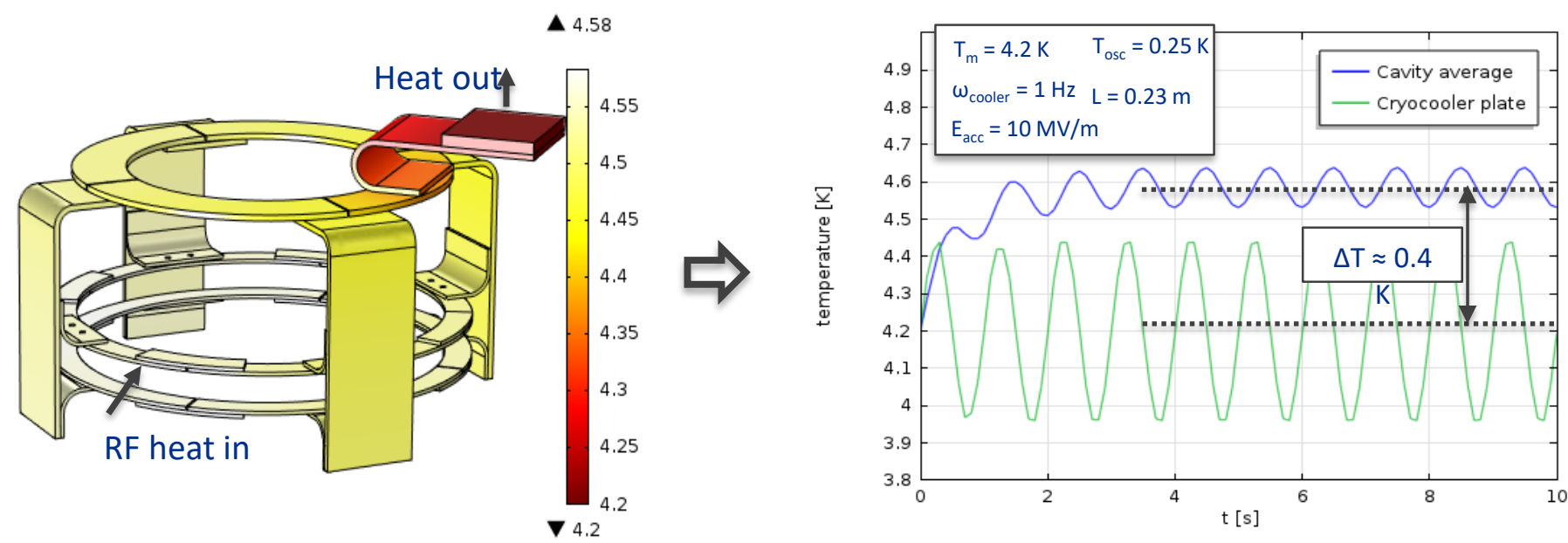

Cold head(s) of the cryocooler(s) connected to cavities by high purity aluminum

LDRD grant \$1.4 M

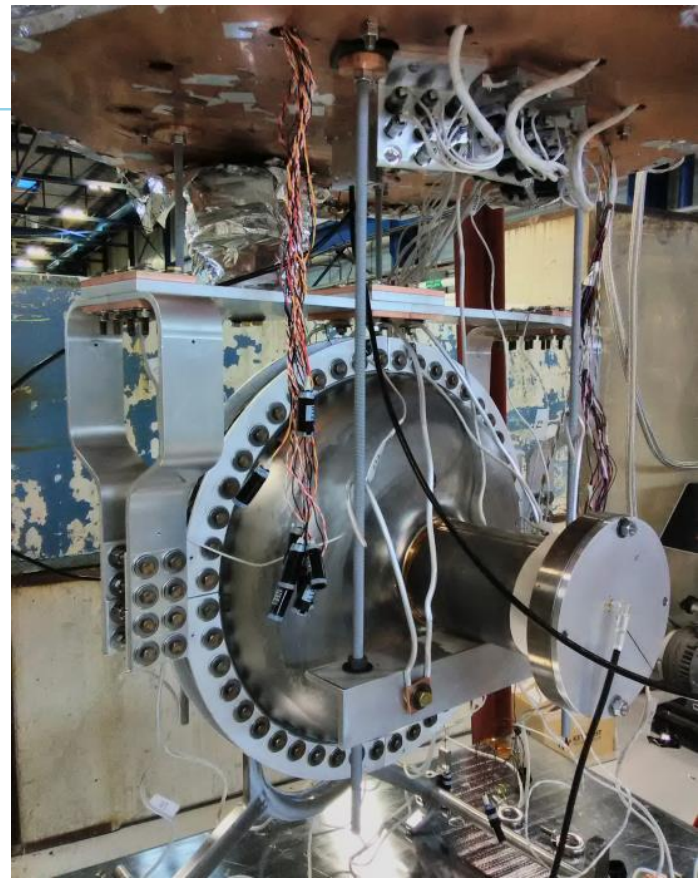

Single cell SRF cavity ready for $4 \mathrm{~K}$ RF testing with a cryocooler

US patent applications \#15/280,107 \#14/689,695 


\section{Push of a button to reach $4.2 \mathrm{~K}$}

- Selection, procurement, and test of cryocoolers

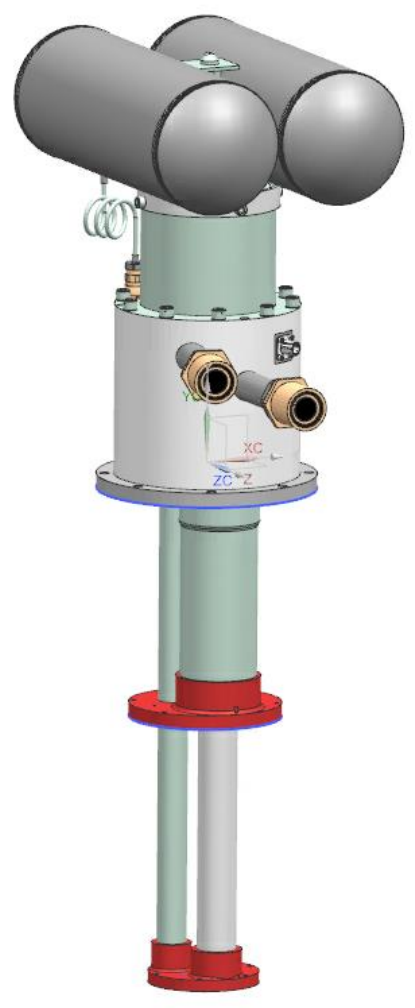

\section{Cryomech PT420}

- Highest cooling power in the market

- Low vibrations, low maintenance

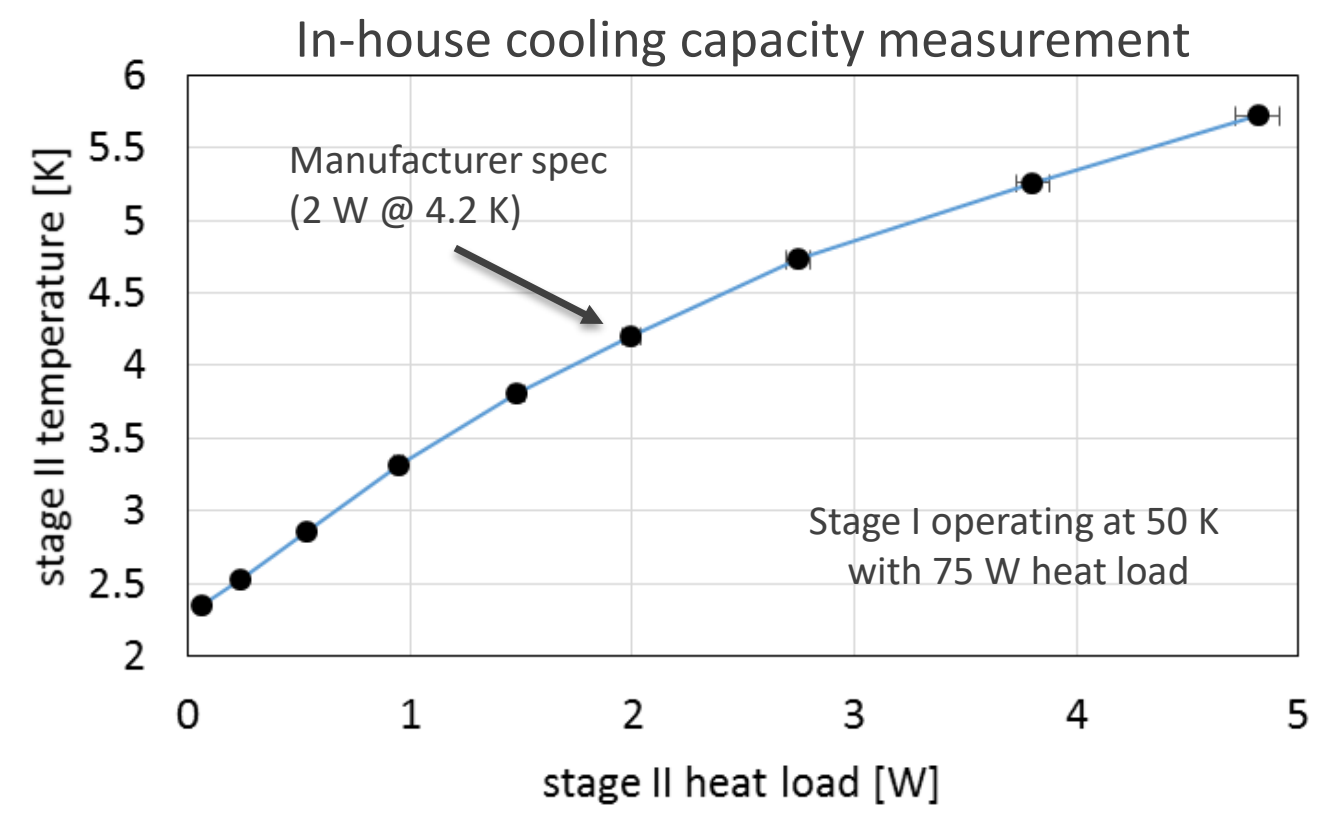




\section{Impact: publications, talks, and media coverage}

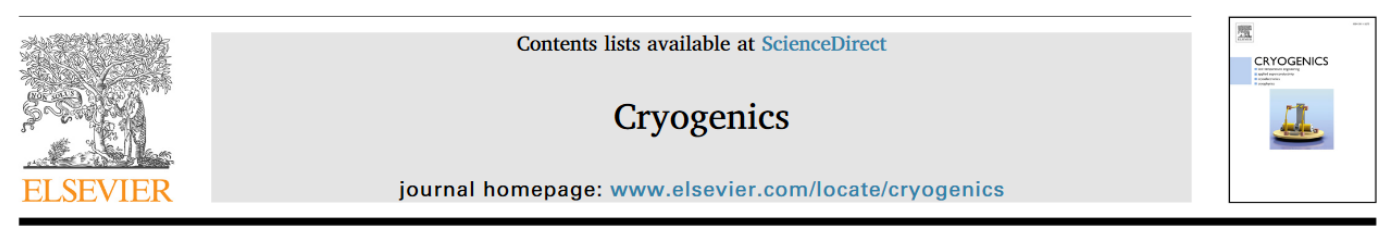

Thermal resistance of pressed contacts of aluminum and niobium at liquid helium temperatures

R.C. Dhuley*, M.I. Geelhoed, J.C.T. Thangaraj

Fermi National Accelerator Laboratory, Batavia, IL 60510, USA

- IEEE IEEE Transactions on Applied Superconductivity Thermal link design for conduction cooling of SRF cavities using cryocoolers

R. C. Dhuley, R. Kostin, O. Prokofiev, M. I. Geelhoed, T. H. Nicol, S. Posen, J. C. T. Thangaraj, T. K. Kroc, and R. D. Kephart

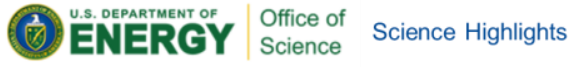

Cryogen-free Superconducting RF Cavity

A team from Fermilab has demonstrated cryogen-free operation of a niobium superconducting radiofrequency cavity.

\section{TechConnect $20 \overline{\text { th ANNIVERSARY }}$ WORLD INNOVATION MAY 13-16, 2018 CONFERENCE \& EXPO ANAHEIM, CA}

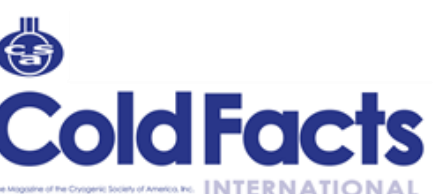

Towards cryogen-free SRF particle accelerators 


\section{Low-heat loss coupler for compact SRF accelerator.}

At the first stage the coupler of PIP-II project - a major science project at Fermilab will be used. This coupler has a similar design, but it was designed for $100 \mathrm{~kW}$ and cryogenic properties of this coupler are worse then properties of coupler for compact SRF accelerator.

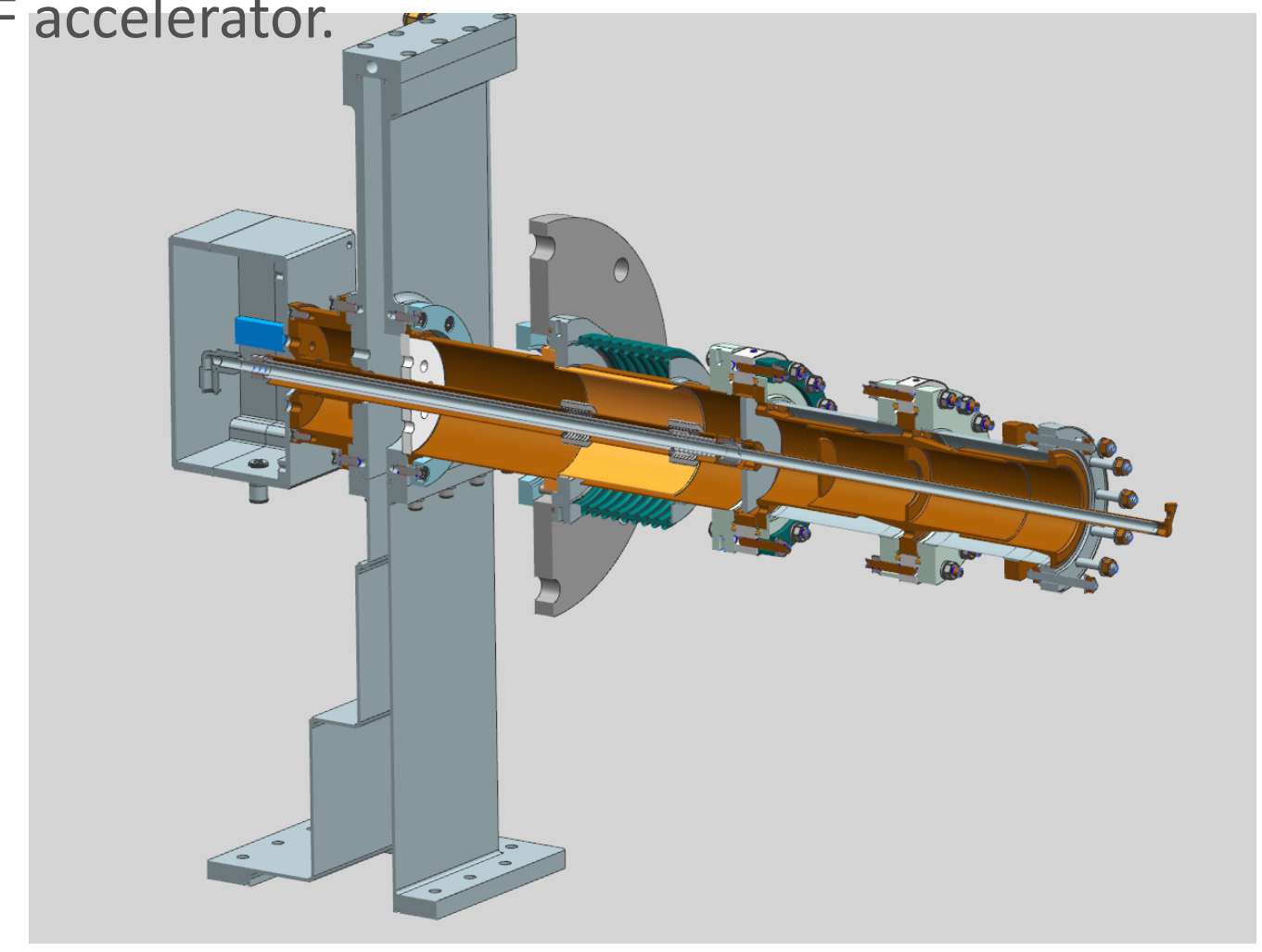

Two PIP-II couplers are under production. 


\section{Beam Physics: Simulated Integrated Electron Gun}

Reduces size and complexity

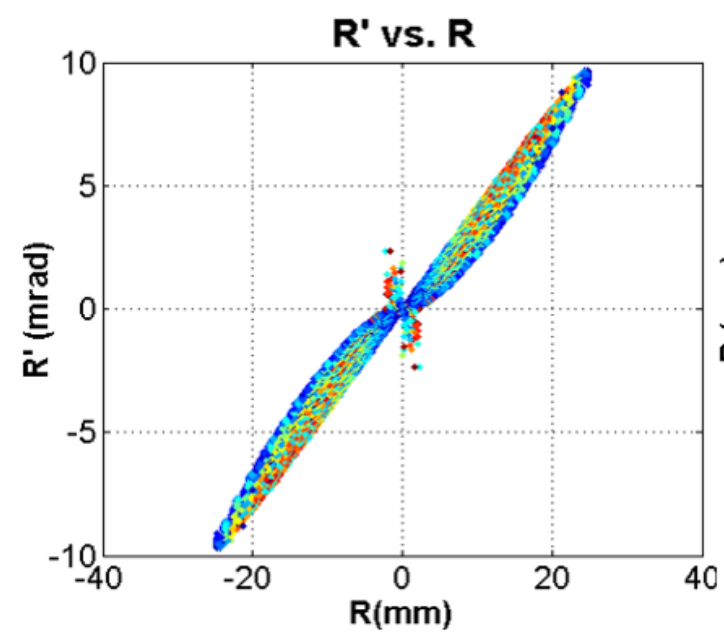

\begin{tabular}{|l|c|}
\hline & Value \\
\hline Electron energy & $9 \mathrm{MeV} \pm 5 \%$ \\
\hline Current modulation range & $0.1 \mu \mathrm{A}-1 \mathrm{~mA}$ \\
\hline Beam loss at 4K & $<0.5 \mathrm{~W}$ \\
\hline Cathode backward bombardment & $<1 \mathrm{~W}$ \\
\hline Cathode blackbody radiation & $<200 \mathrm{~mW}$ \\
\hline
\end{tabular}
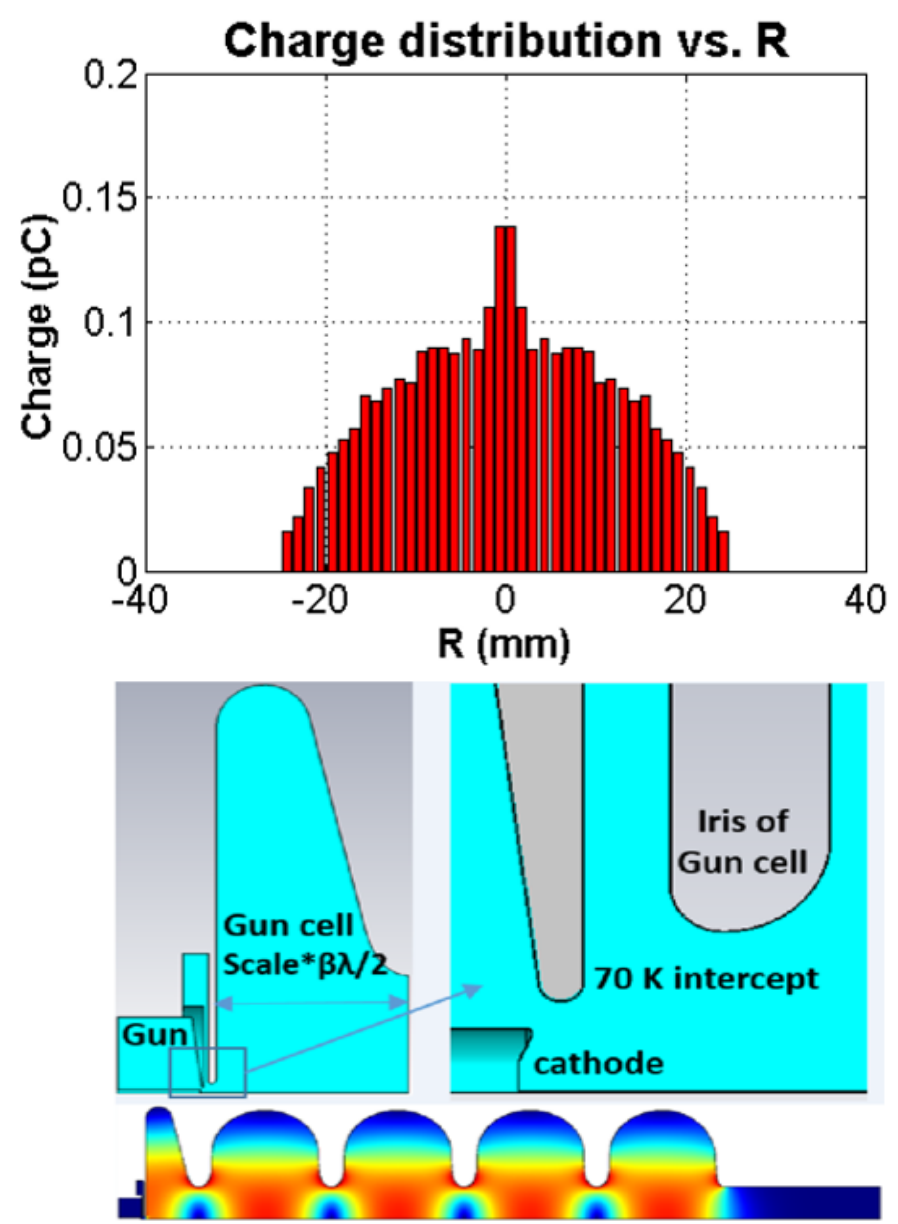


\section{Simulations of the Cavity}

- (Top) Bunch acceleration along the cavity (RMS energy).

- (Bottom Left) Transverse $\left(x-x^{\prime}\right)$ phase-space distribution.

- (Bottom Right) Transverse beam charge density distribution.
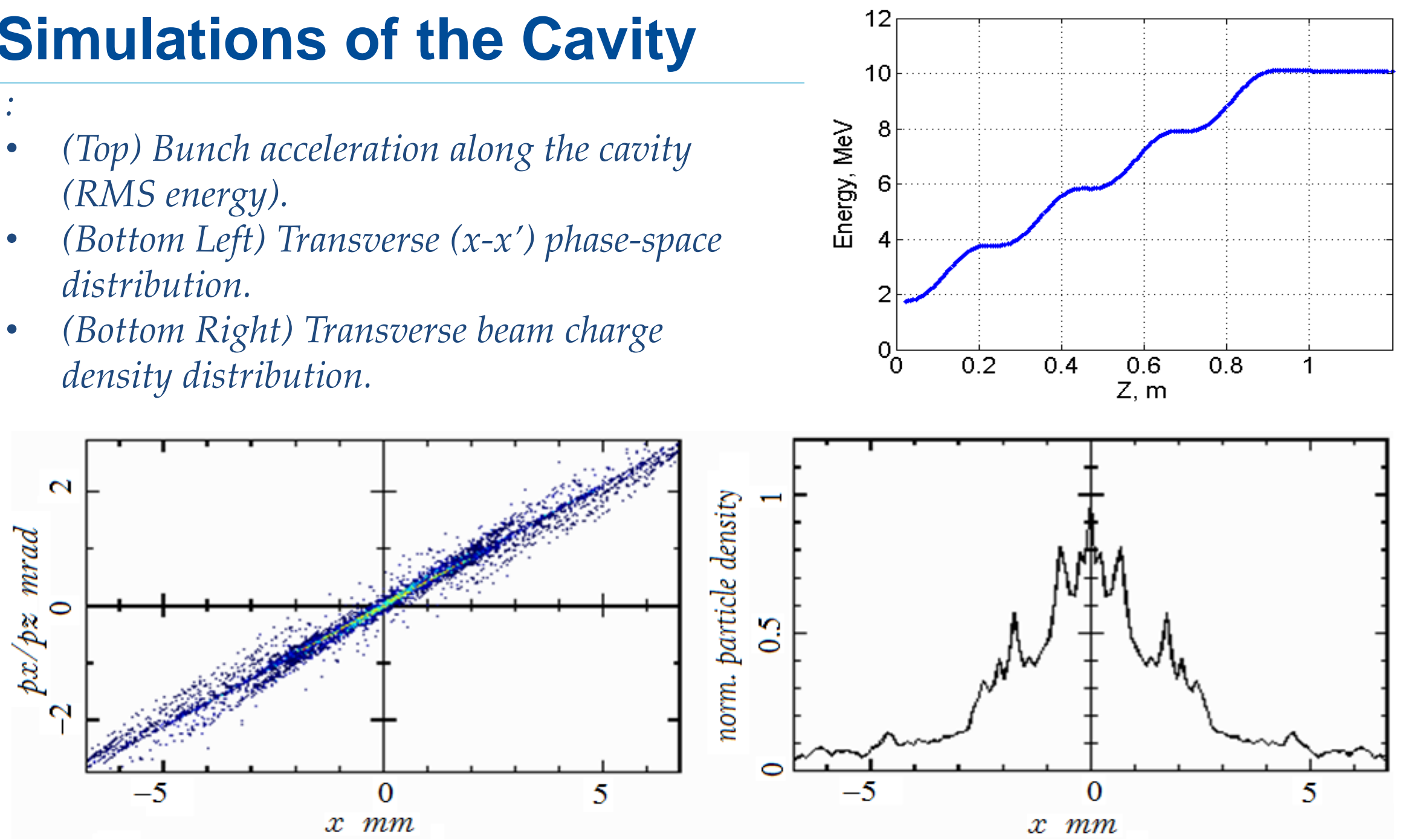

Particle losses in simulations $<10^{-5}$. (This is important for the heat budget) 


\section{Beam Envelope Simulation from external injection (10 MW)}

$3 \sigma$ beam envelopes
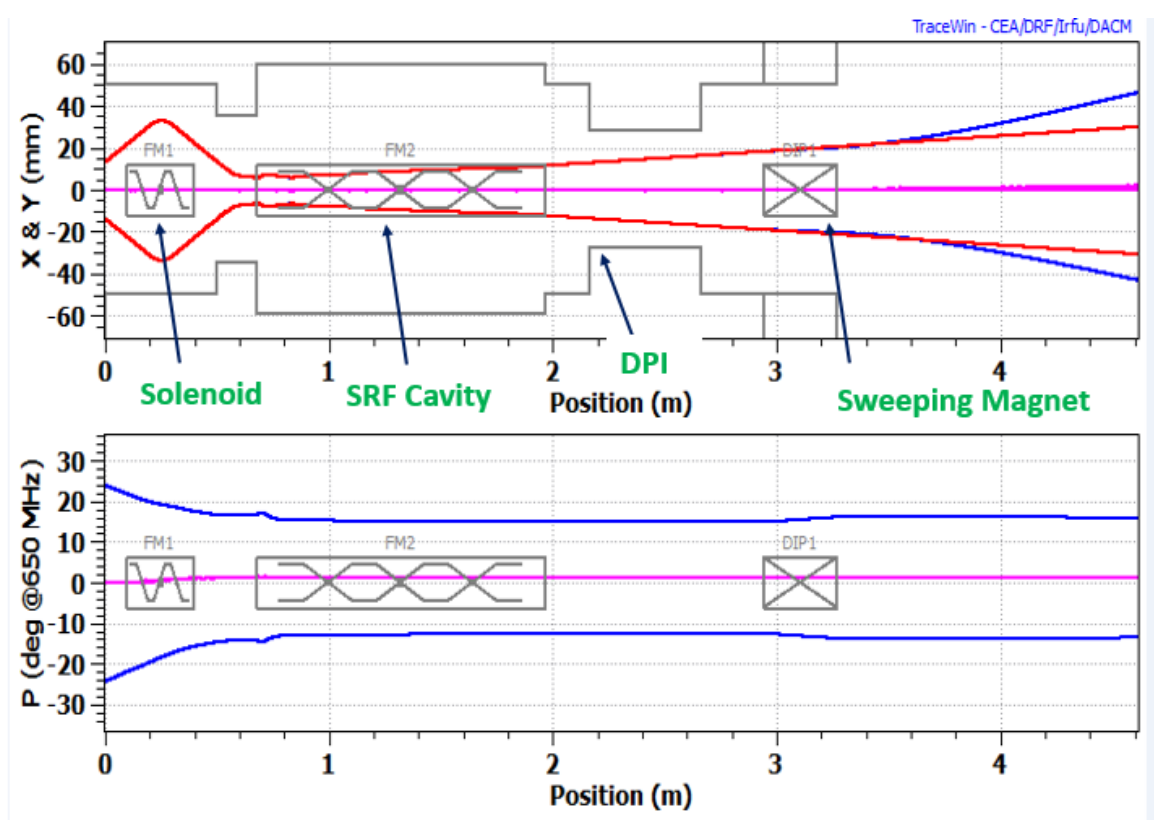

Beam Energy

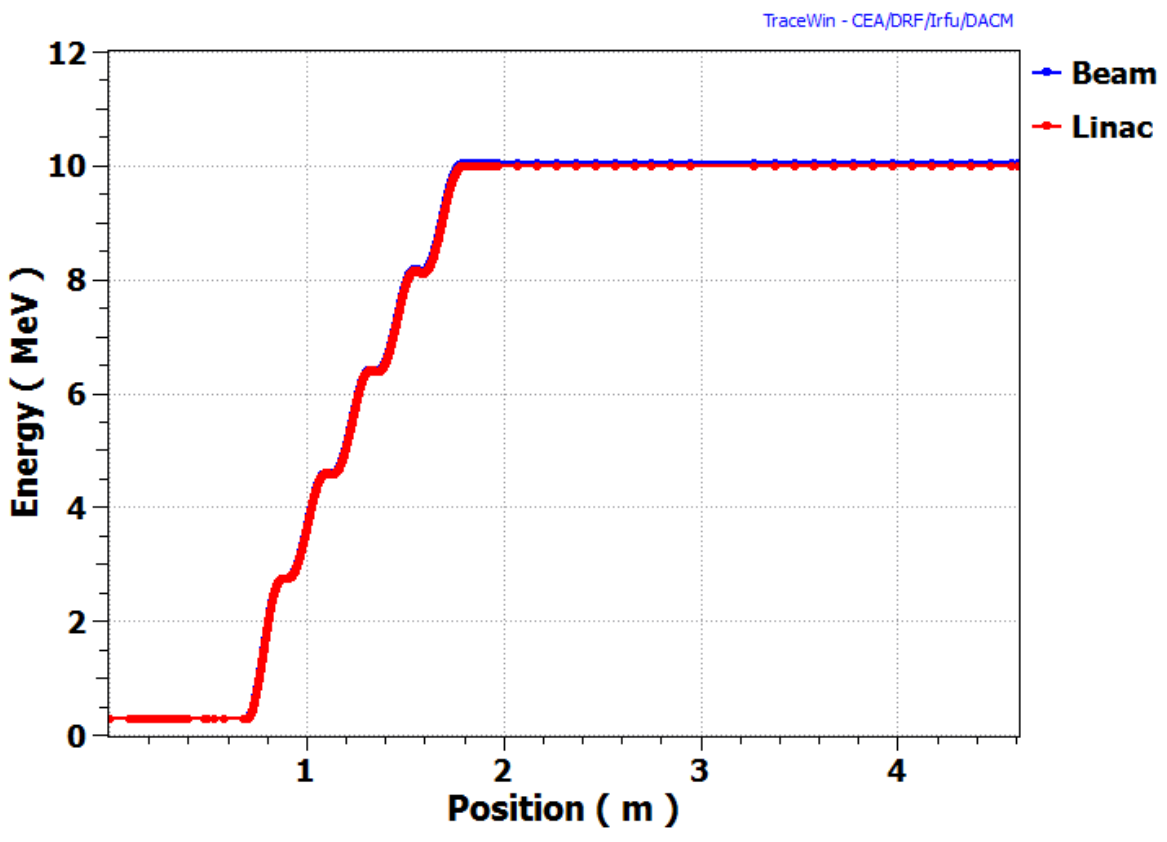

- Beamdynamics simulation was performed using TRACEWIN.

- $1 \mathrm{M}$ macro particles corresponds to $100 \mathrm{~mA}$ beam current was tracked through the beamline.

- Initial distribution was generated using Twiss parameters and beam emittance obtained from RF gun simulation . 


\section{Beam Simulation from external injection (10 MW)}

Ele \#37 [4.3145 m] NGOOD : 999573 / 1000000
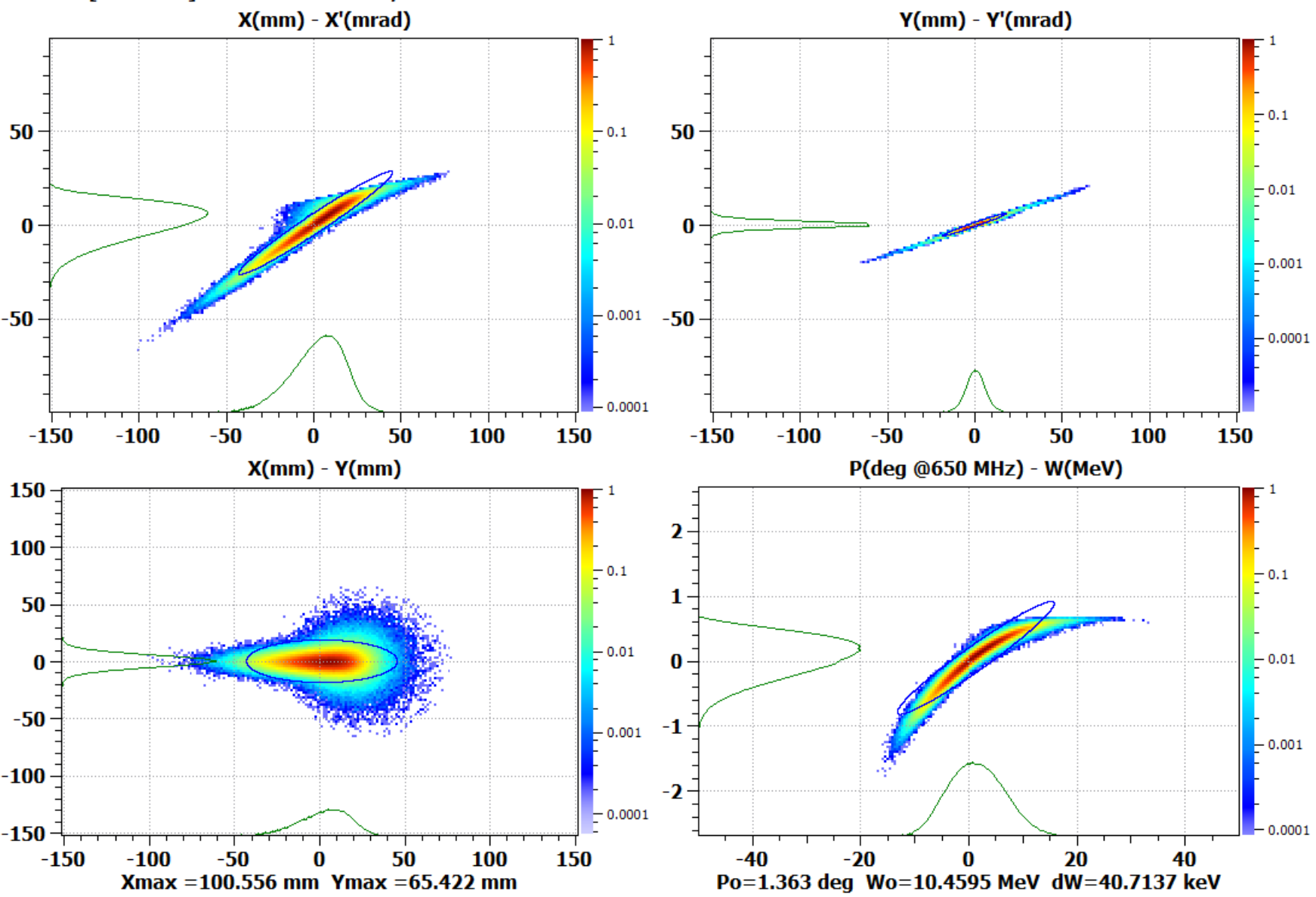

- Output beam distribution at the end of the beamline (very low losses!) 
Challenges

- Magnetic shield

- SRF cavities are very sensitive to trapped magnetic fields

- need < few $m G$ to keep RF heat dissipation under cryocooler budget

- penetrations and access ports are to be carefully designed

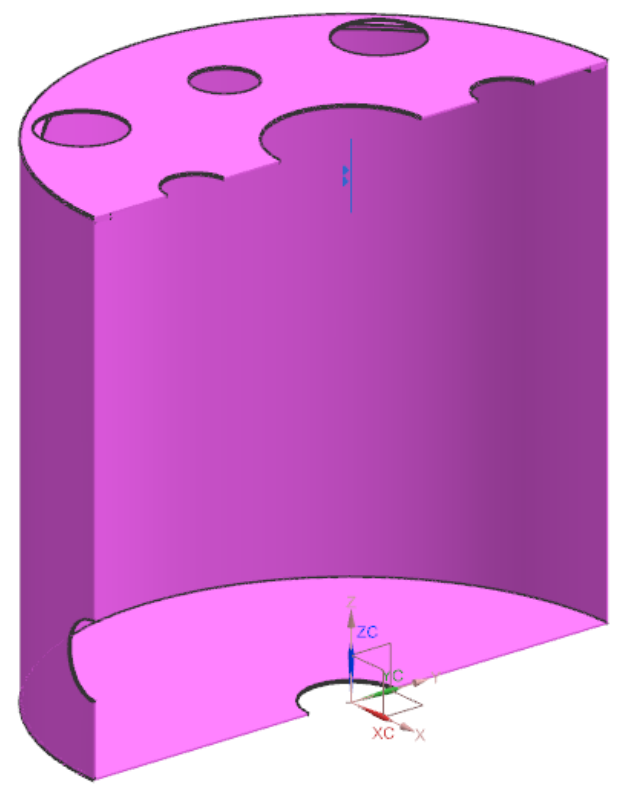

Magnetic shield with penetrations
- Interfaces with e-gun, power coupler, beam outlet port

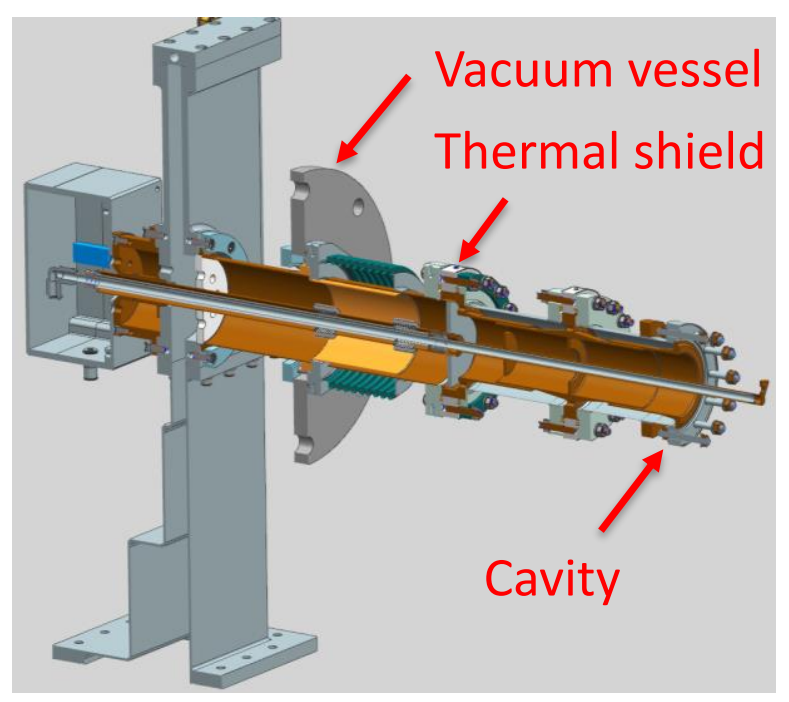

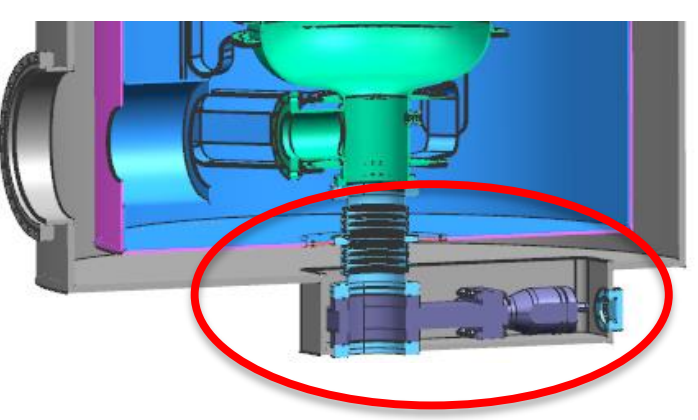

Shut-off valve at beam outlet

32

Jayakar C Thangaraj| Seminar

Fermilab 


\section{Food and Medical Sterilization}

- Electron beams can be used directly or to create $x$-rays to accomplish many tasks currently accomplished with Co60 radioisotopes

- FNAL recently completed a study for NNSA on impediments to change.

- One impediment is the need for high power, reliable, cost effective electron accelerators

- Need materials data on effects of gamma, electrons, x-ray to enable recertification of legacy products

- New Possibilities:

- Cheap, compact, simple, industrial electron accelerators can enable "in line" sterilization at the point of manufacture 


\section{Application: Waste Water/Sludge Treatment}

- Electron beams create highly reactive species

- Demonstrated effective for:

- Disinfection of municipal bio-solids

- Destruction of organics, pharmaceuticals

- Yet, despite demonstrations $\sim$ no market penetration

- Why? Municipalities are conservative; don't finance R\&D

- High power, cost effective, industrial accelerators have not been available to deploy* e.g. * http://science.energy.gov/ /media/hep/pdt/accelerator-rdstewardship/Energy_Environment_Report_Final.pdf

- Compact SRF accelerators can change this situation

- IARC is partnered with the Chicago Metropolitan Water Reclamation District (MWRD)

- Operate largest treatment plant in the world

- Identified multiple areas to evaluate EB

- Bio-solids, cell lysis, destroy pharmaceuticals

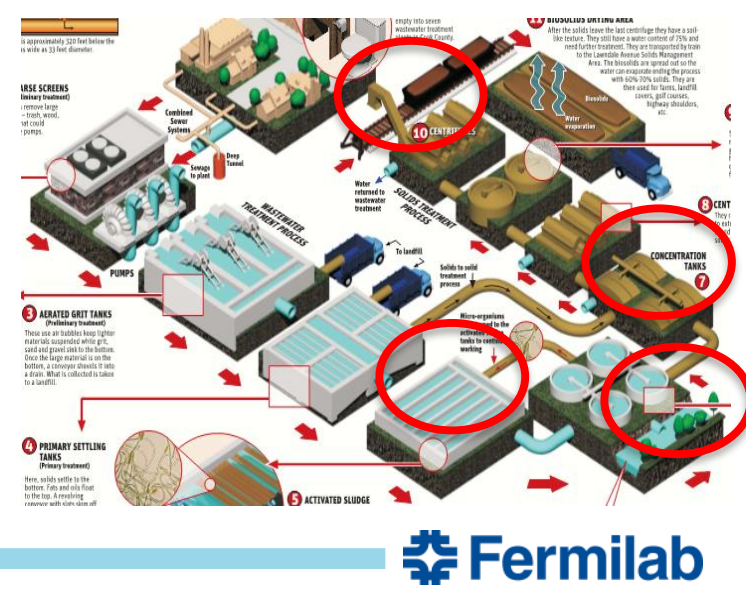

Sept-2019 


\section{Processing cost per Application}

(acknowiedgment to: Gianiuigi Ciovati, JLab)

\begin{tabular}{|c|c|c|c|}
\hline & \multicolumn{2}{|c|}{$1 \mathrm{MeV}, 1 \mathrm{MW}$} & $10 \mathrm{MeV}, 1 \mathrm{MW}$ \\
\hline & \multicolumn{2}{|c|}{ WASTEWATER } & SLUDGE \\
\hline Dose requirement & $1 \mathrm{kGy}$ & $4 \mathrm{kGy}$ & $10 \mathrm{kGy}$ \\
\hline Processing cost & $\$ 0.13 / \mathrm{m}^{3}$ (\$0.482/kgal) & $\$ 0.51 / \mathrm{m}^{3}$ (\$1.93/kgal) & $\$ 19.7 /$ dry ton \\
\hline Daily Processed Volume & $\begin{array}{c}45,000 \mathrm{~m}^{3} \\
\left(11.9 \mathrm{Mgal}^{2}\right)\end{array}$ & $\begin{array}{l}11,250 \mathrm{~m}^{3} \\
\text { (3.0 Mgal) }\end{array}$ & $\begin{array}{c}278 \text { dry ton ( } 1.3 \mathrm{Mgal} \\
\text { with } 25 \% \text { biosolid } \\
\text { waste) }\end{array}$ \\
\hline Required Flow Rate (gpm) & 9,050 & 2,260 & 984 \\
\hline Comments [1] & $\begin{array}{l}\text { Color, Odor, Coliform } \\
\text { bacteria removal }\end{array}$ & Kill >99\% of bacteria & $\begin{array}{l}\text { Inactivate some } \\
\text { radiation resistant } \\
\text { organisms }\end{array}$ \\
\hline $\begin{array}{l}\text { [1] S. Henderson and T.D. Waite, } \\
\text { (https://science.energy.gov } / \sim / \text { med }\end{array}$ & $\begin{array}{l}\text { Workshop on Energy and Enviro } \\
\text { dia/hep/pdf/accelerator-rd-stew }\end{array}$ & $\begin{array}{l}\text { nental Applications of Accelerat } \\
\text { dship/Energy_Environment_Re }\end{array}$ & $\begin{array}{l}\text { rs, U.S. Deptof Energy, June } 24 \\
\text { ort_Final.pdf) }\end{array}$ \\
\hline
\end{tabular}




\section{Many emerging areas that SRF accelerators can add value to}

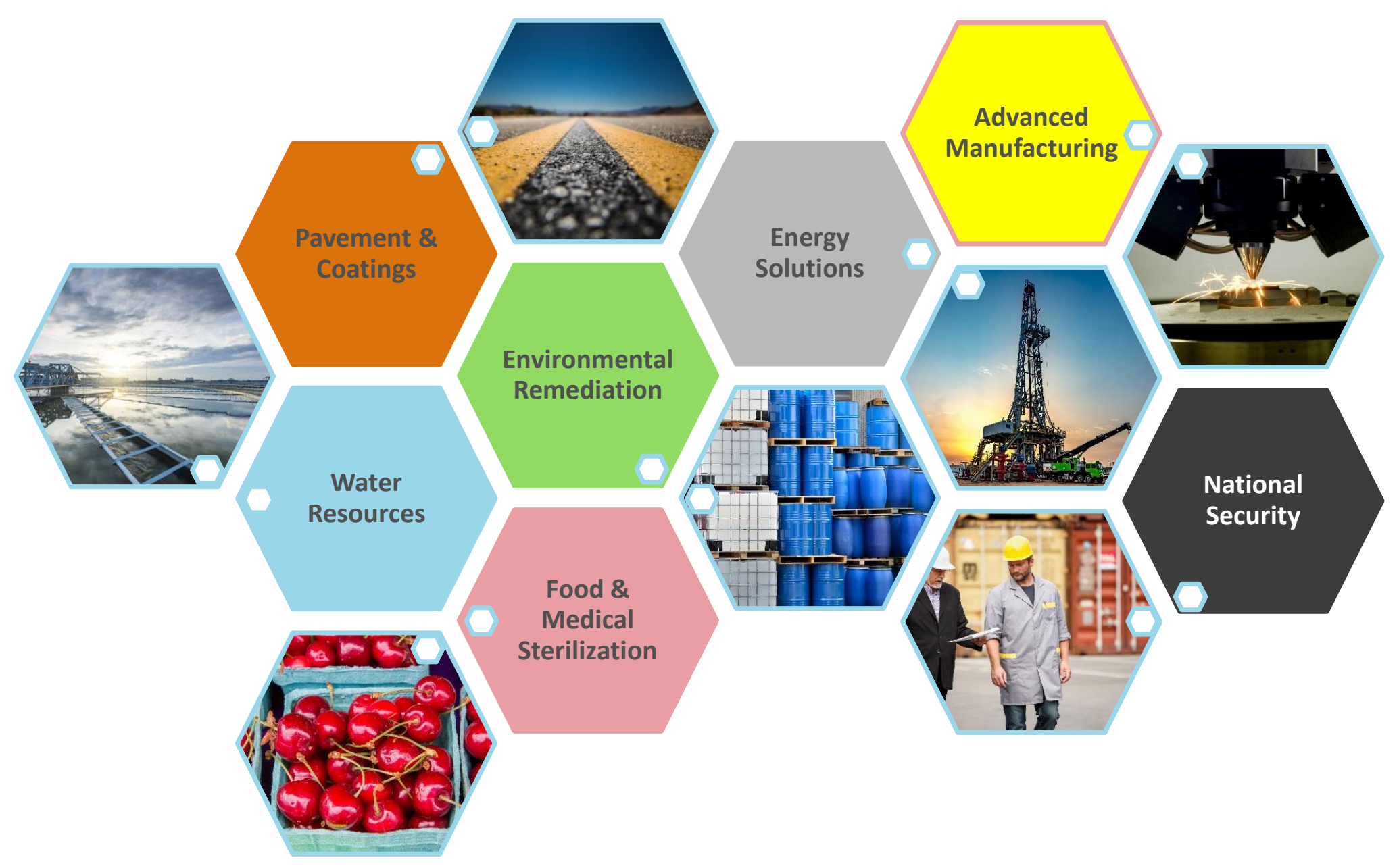




\section{Partnerships and Technology Transfer}

\section{Home}

Contact

News

Resources

Partnering With Fermilab

\section{Becoming a Partner}

Letters of Support

Partnering Agreements

Reporting Success

Technology Portfolios

Accelerator Technologies

- Compact SRF Accelerator

- Pavement

- Magnetron

- 3D Additive Manufacturing with High Power Electron Gun

- Conduction Cooling

- Low Heat Leak Power Coupler

" Fast Faraday Cup

Computers \& Information Science

Detector Technologies

Engineering Technologies

Fnvironmental \& Safetv

\section{Compact SRF Accelerator}

\section{Technology Summary}

Accelerators developed for science now are used broadly for industrial, medical, and security applications. Over 30,000 accelerators touch over $\$ 500 \mathrm{~B} / \mathrm{yr}$ in products producing a major impact on our economy, health, and well-being. Industrial acc elerators must be cost-effective, simple, versatile, efficient, and robust. Many industrial applications require high average beam power.

\section{The Invention}

Exploiting recent advances in Superconducting Radio Frequency (SRF) cavities and RF power sources as well as innovative solutions for the SRF gun and cathode system we have developed a design for a compact SRF high-average power electron linac. Capable of $>250 \mathrm{~kW}$ average power and continuous wave operation, this accelerator produces electron beam energies up to $10 \mathrm{MeV}$.

\section{Benefit}

Small and light enough to mount on mobile platforms, Fermilab Compact SRF accelerators enable new in-situ environmental remediation, in-situ crosslinking of materials, and security applications. More importantly, this accelerator will be the first of a new class of simple, turn-key SRF accelerators.

\section{Applications and Industries}

- Industry

- Medicine

- Security

- Science

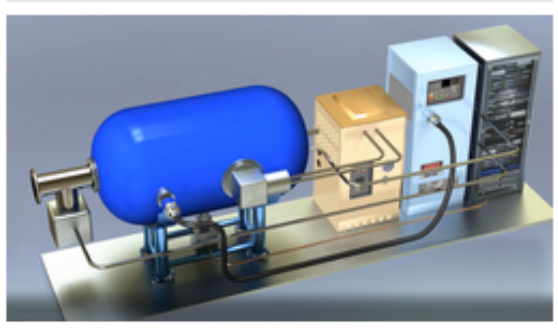

Invention Details

Patent Status: Multiple patents pending

\section{Contact:}

Aaron G Sauers, CLP

630-840-4432

asauers@fnal.gov

Fermilab, MS 312- PO Box 500

Batavia, IL 60510 


\section{A simple SRF accelerator for industrial application}

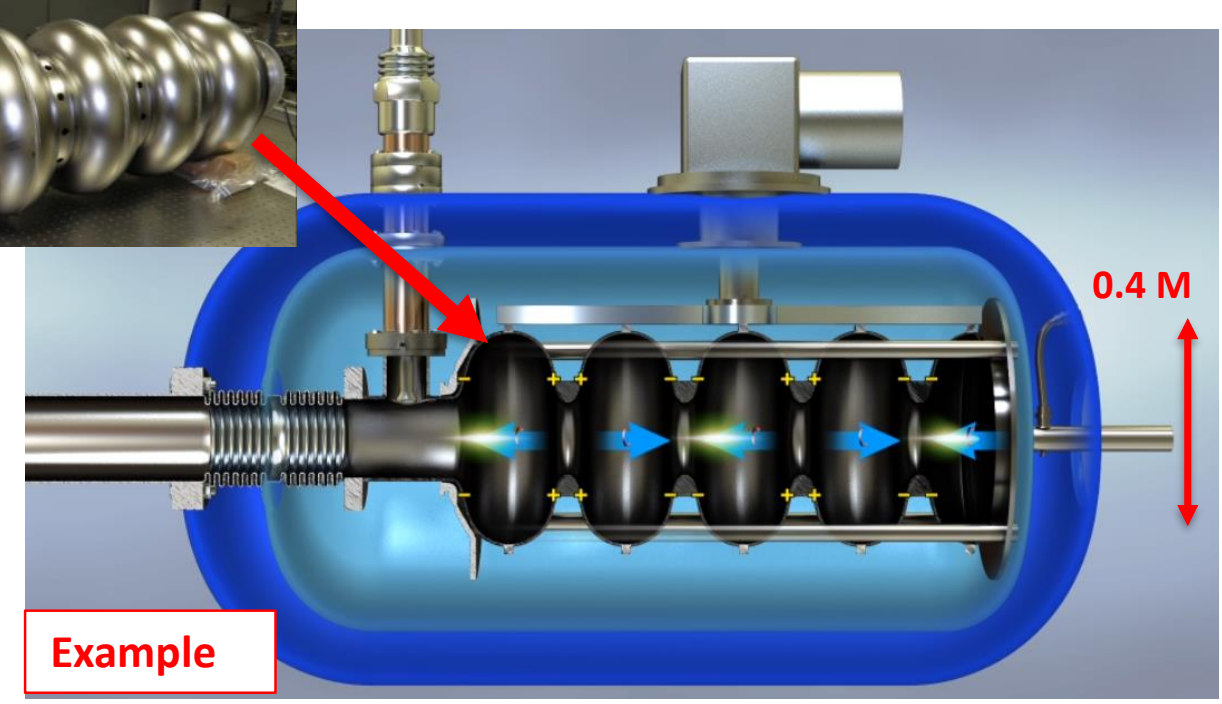

Final machine parameters

- Energy: $10 \mathrm{MeV}$

- Power: $250 \mathrm{~kW}-1 \mathrm{MW}$

- Compact

- Simple, reliable

- Affordable

The Illinois Accelerator Research Center at Fermilab is partnered with U.S. government agencies to create the first article of an entirely new class of industrial SRF-based electron accelerators that use no liquid cryogens

Thank you!!! 